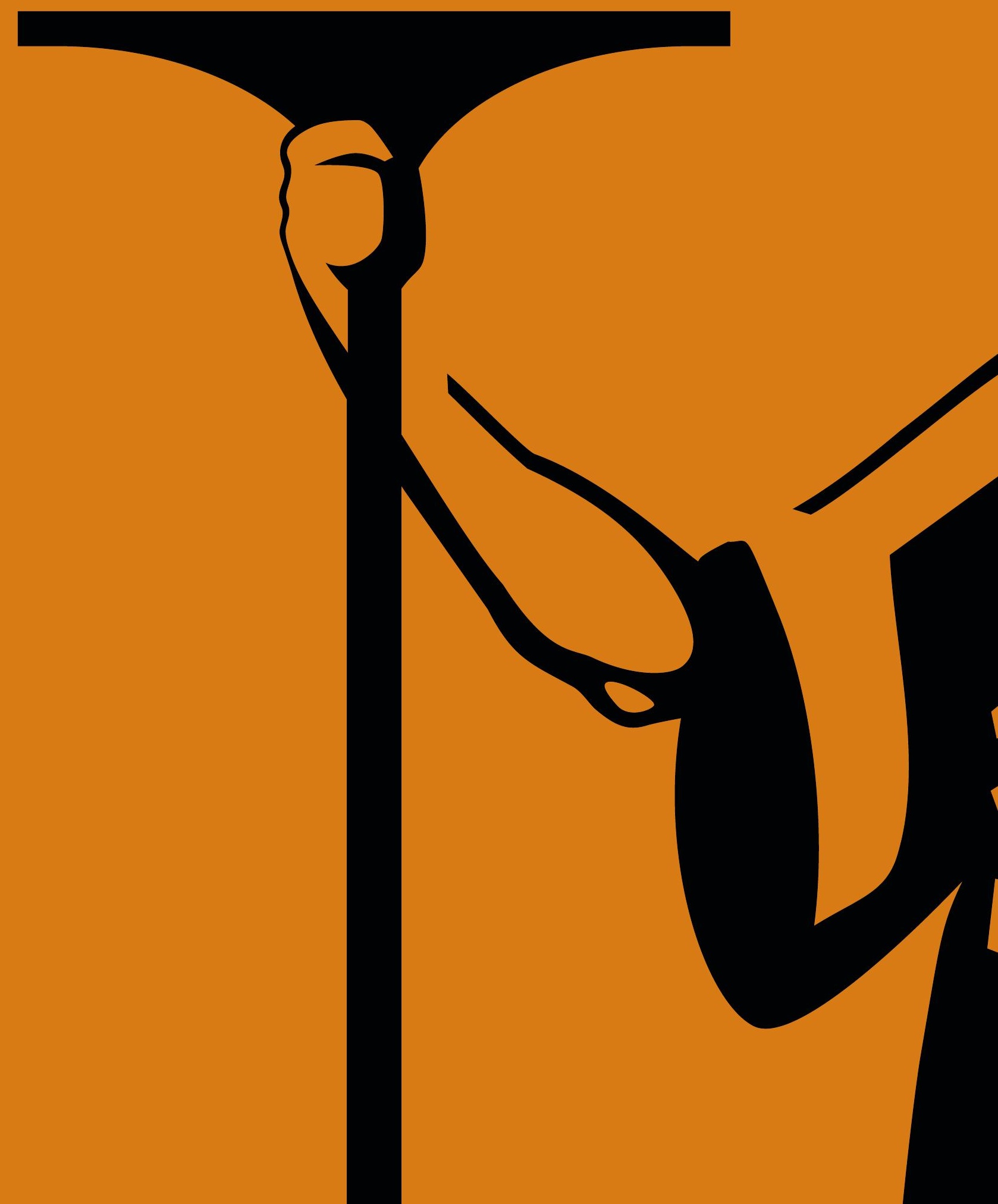


XVI SEMANA DE DIVULGAÇÃO CIENTÍFICA DA FACULDADE DE MEDICINA VETERINÁRIA

\section{ENCONTRO REGIONAL DE SAÚDE ÚNICA EM PARASITOLOGIA (PARTE II)}

11 de novembro de 2017

Faculdade de Medicina Veterinária da Unesp, Araçatuba/ SP, Brasil

\section{AUMENTO DOS MARCADORES INFLAMATÓRIOS (IL-6, IL-8 E PROTEÍNA C REATIVA) EM CÃES OBESOS}

Increase in inflammatory markers (Il-6, Il-8 and C reative protein) in obese dogs

MENEZES, A. R. P.; BOSCO, A. M.; ALMEIDA, B. F. M.; VALADARES, T. C.; PEREIRA, A. A. F.; BAPTISTIOLLI, L.; HOFFMANN, D. J.; CIARLINI, P. C.

Resumo: A obesidade é a doença nutricional mais comum em cães. Atualmente as citocinas na obesidade são consideradas importantes fatores na ativação e controle da inflamação de baixo grau. Na obesidade grave, quando comparado ao fígado, o tecido adiposo produz de 100 a 1000 vezes mais citocinas pró-inflamatórias. Até o momento, os mecanismos pelos quais a obesidade afeta os marcadores inflamatórios na espécie canina ainda não estão totalmente elucidados. Este trabalho testa a hipótese de que as concentrações plasmáticas dos marcadores inflamatórios aumentam na obesidade canina. Para isso, 84 cães foram agrupados de acordo com o escore de condição corporal (ECC) de Laflamme (1997): controle (ECC 4 ou 5), sobrepeso (ECC 6 ou 7 ) e obeso (8 ou 9). A resposta inflamatória foi avaliada a partir da determinação por ELISA das citocinas IL-6, IL-8 e proteína $C$ reativa, com o emprego de reagentes comerciais espécie-específicos. Comparado ao grupo controle $(354,5 \pm 217,5 \mathrm{ng} / \mathrm{mL})$, a IL-6 plasmática de cães obesos $(553,8 \pm 293,8 \mathrm{ng} / \mathrm{mL})$ foi significativamente maior $(\mathrm{p}=0,0301)$, porém não houve aumento relevante nos cães com sobrepeso $(450,2 \pm 201,3 \mathrm{ng} /$ $\mathrm{mL}$ ). No grupo obeso, a IL-8 plasmática foi significativamente maior $(189,9 \pm 186,2 \mathrm{ng} / \mathrm{mL}, \mathrm{p}=0,003) \mathrm{em}$ relação aos grupos controle $(145,0 \pm 122,3 \mathrm{ng} / \mathrm{mL})$ e sobrepeso $(531,7 \pm 373,8 \mathrm{ng} / \mathrm{mL})$. A proteína C plasmática teve um aumento significativo $(\mathrm{p}=0,026)$ nos cães obesos $(7,21 \pm 7,12 \mathrm{ug} / \mathrm{mL})$ quando comparada ao grupo controle $(3,08 \pm 1,85 \mathrm{ug} / \mathrm{mL})$, entretanto não houve diferença estatística com os sobrepesos $(4,77 \pm 3,82 \mathrm{ug} /$ $\mathrm{mL}$ ). A proteína $\mathrm{C}$ reativa e a IL- 6 apresentam concentrações elevadas em cães obesos, em comparação ao grupo controle. Resultados semelhantes de outros estudos foram observados. A IL-8 plasmática foi significativamente maior no grupo obeso e sobrepeso, fato não observado por Frank et al. (2015), no entanto, em humanos já se sabe que esta citocina apresenta maior concentração durante a obesidade. O conjunto dos resultados confirma a hipótese inicial de que em cães obesos há o aumento das citocinas pró-inflamatórias e à semelhança do que já descrito em humanos, na obesidade canina também ocorre uma inflamação crônica.

Pallavras-chave: Obesidade. Canino. Inflamação. Citocinas.

\section{SAZONALIDADE DO ENVIO DE AMOSTRAS DE MORCEGOS PARA DIAGNÓSTICO DE RAIVA DO MUNICÍPIO DE ARAÇATUBA/SP DE 2013 A 2016}

Sazonality of the sending of samples of bats for diagnosis of anger of the municipality of Araçatuba/SP from 2013 to 2016

FAVARO, A. B. B. B. C.; BOTEGA, A. M.; ZANCHETTA, I. L.; LORENA, L. L. G.; QUEIROZ, L. H.; MARINHO, M.

Resumo: A raiva é uma doença viral, altamente letal, que deve ser controlada, dentre outras medidas, por meio da vigilância passiva, que consiste no envio de amostras suspeitas para o diagnóstico laboratorial. As técnicas utilizadas no Brasil são a Reação de Imunofluorescência Direta (RIFD) e o Isolamento Viral em Camundongos (IVC). O Laboratório de Raiva da Universidade Estadual Paulista de Araçatuba (Unesp) realiza esse diagnóstico na região noroeste do estado de São Paulo desde o ano de 1993, recebendo amostras provenientes das prefeituras que realizam a vigilância passiva. Este serviço faz parte do Programa Estadual de Controle da Raiva. Especificamente na cidade de Araçatuba, a raiva na espécie canina foi controlada no final da década de 1990, porém o vírus continua circulando entre morcegos, principalmente insetívoros e frugívoros, que são facilmente encontrados nos centros urbanos (CARVALHO et al., 2011; QUEIROZ et al., 2009) e podem entrar em contato com animais de estimação, principalmente os gatos, que possuem o hábito de caça (GENARO, 2010). Este trabalho realizou um estudo retrospectivo dos 
registros do laboratório, para avaliar a existência de uma sazonalidade no envio de amostras de morcegos do município de Araçatuba. O último morcego positivo para raiva foi encontrado na cidade no ano de 2012, por isso foram selecionados os anos subsequentes para avaliar a qualidade da vigilância em um período com ausência de casos positivos. No período de 2013 a 2016 foram enviados 333 morcegos para o laboratório de raiva da Unesp Araçatuba, e a média de envio foi de 66 animais por ano, principalmente durante a primavera $(47,45 \%)$. Este resultado está dentro do esperado, pois se trata do período de maior atividade das espécies encontradas, as quais ficam mais expostas às intempéries e acidentes, inclusive com humanos. A maioria foi proveniente de bairros centrais, aonde essas espécies facilmente se adaptaram. Esta situação é preocupante, pois nesse mesmo período o Sistema de Informação do Programa Nacional de Imunizações (SI-PNI) indicou que a cobertura vacinal de cães e gatos não atingiu em todos os anos a sua meta de $80 \%$. Além disso, até o mês de setembro de 2017 houve uma acentuada queda no envio de morcegos para diagnóstico no município, com 35 amostras. Esses dados servem de alerta, pois em outros municípios do estado de São Paulo, têm sido encontrados morcegos, reservatórios do vírus da raiva, vivendo nos centros urbanos, onde encontram abundância de alimento e podem ter contato acidental com animais domésticos não imunizados, que convivem próximos às pessoas.

Palavras-chave: Raiva. Diagnóstico. Vigilância. Araçatuba.

\section{O PAPEL DO MÉDICO-VETERINÁRIO NO ATENDIMENTO DE PESSOAS PORTADORAS DO TRANSTORNO DE ACUMULAÇÃO}

The role of the veterinary doctor in the care of persons with the accumulation disorder

FAVARO, A. B. B. B. C.; MARQUES, A. E. G. W.; REGINALDO, G. M. S.; RAMOS, T. O.; QUEIROZ, L. H.

Resumo: O Transtorno da Acumulação (TA) é uma psicopatologia na qual o indivíduo sente a necessidade de coletar objetos ou animais, e tem a dificuldade para se desfazer de tais posses e, por consequência, surgem problemas de organização associados ao seu ambiente de convívio. O comportamento de acumular prejudica diversos aspectos da vida cotidiana, principalmente no âmbito social e ocupacional, dificultando o convívio com esses indivíduos. Por isso, pessoas com características de TA podem ficar isoladas. No ano de 2017, durante o desenvolvimento da disciplina de Educação e Comunicação em Saúde do Programa de Pós-Graduação em Ciência Animal da Faculdade de Medicina Veterinária da Universidade Estadual Paulista (Unesp Araçatuba), os alunos foram incentivados a trabalhar com esse tema por ser uma problemática de abordagem multiprofissional, similar ao perfil dos atuais alunos de pós-graduação desse programa (enfermeiros, nutricionistas, biomédicos, dentistas, fisioterapeutas e médicos-veterinários). Assim, foi desenvolvido um projeto piloto, um questionário semiestruturado destinado a avaliar o grau de conhecimento e o comportamento de diferentes grupos sociais frente ao TA. Este trabalho trata da análise do conhecimento e comportamento dos médicos-veterinários do município de Araçatuba/ SP. Foram entrevistados 16 médicos-veterinários de quatro estabelecimentos diferentes. Foi observado que $100 \%$ dos entrevistados relataram que já haviam atendido tutores possivelmente portadores do TA, entretanto, somente $60 \%$ dos profissionais sabiam definir a psicopatia estudada. As principais características que levaram à suspeita foram o elevado número de animais (57\%) e a falta de higiene (29\%) dos tutores. Quando questionados sobre as atitudes tomadas frente ao caso, $84 \%$ dos médicos-veterinários relataram fornecer orientações verbais, $37 \%$ também executaram algum procedimento gratuito, como vacinação, vermifugação, consultas ou doação de ração e $11 \%$ não tomaram nenhuma atitude frente ao caso. Esses resultados indicam a necessidade de maior esclarecimento dos médicos-veterinários sobre essa psicopatologia e a conscientização para a importância da identificação desses tutores para o desencadeamento de medidas de assistência futura. Vale ressaltar a importância da proximidade destes profissionais com os portadores de TA, tendo em vista que tais indivíduos apresentam isolamento social. As orientações transmitidas durante estas consultas precisam ser específicas para esse público e focadas também na saúde humana. Isso posto, ressalta-se a importância da atuação do médico-veterinário na saúde animal e humana e a necessidade de inclui-lo no fluxo de abordagem e atendimento dos pacientes com TA.

Palavras-chave: Atendimento. Acumuladores. Médico-veterinário. 
04. DOENÇA VALVAR CRÔNICA DE MITRAL ASSOCIADA A COÁGULO EM ÁTRIO ESQUERDO DE UM CÃO: RELATO DE CASO

Cronic mitral valve disease associated to clot in the left atrium of a dog: case report

MARQUES, A. E. G. W.; MARQUES, M. G.; RIBEIRO, M. S.; FARIA, M. C.; ALBUQUERQUE, L. I. L.; PINOTI, L. D. R.; FERREIRA, W. L.

Resumo: Canino, boxer, macho, com nove anos de idade foi atendido no Hospital Veterinário Luiz Quintiliano de Oliveira com queixa de cansaço fácil há um ano, emagrecimento progressivo há um mês e tosse há oito meses. No exame físico foi observado taquicardia e taquipneia, sopro holossistólico grau V/VI com ponto de intensidade máxima em foco mitral, além de pulso rápido e irregular. O eletrocardiograma revelou predomínio de taquicardia sinusal e 42 extrassístoles ventriculares (VPC) polimórficas em oito minutos, sendo oito VPC isolados e 34 bigeminismos. No exame radiográfico foi constatado aumento global do coração e padrão pulmonar compatível com senilidade. No ecocardiograma a valva mitral apresentou-se moderadamente irregular, espessada e hiperecoica, indicando insuficiência severa. Além disso, foi observado aumento severo das câmaras atriais (relação átrio esquerdo/aorta: 3,83 ) e ventriculares esquerda (diâmetro interno do ventrículo esquerdo normalizado: 1,90) e direita, déficit sistólico ventricular esquerdo (fração de encurtamento $29 \%$ e fração de ejeção: $56 \%$ ) e hipertensão pulmonar severa $(79,3 \mathrm{mmHg})$. No átrio esquerdo, por contraste espontâneo, foram visualizadas estruturas com características ecográficas sugestivas de coágulo, medindo aproximadamente $6,9 \mathrm{~cm}$ de diâmetro. À luz das alterações clínicas e ecocardiográficas, a conclusão obtida foi que se tratava de uma doença valvar crônica de mitral. O tratamento prescrito foi maleato de enalapril (o,5 mg/kg/bid), furosemida ( $2 \mathrm{mg} / \mathrm{kg} / \mathrm{bid})$, espironolactona $(2 \mathrm{mg} / \mathrm{kg} / \mathrm{sid})$, pimobendan $(0,25 \mathrm{mg} /$ $\mathrm{kg} / \mathrm{bid}$ ) e clopidogrel (o,7 mg/kg/sid). Após 10 dias, o proprietário referiu melhora do quadro com o início da terapia, porém devido a restrições financeiras não pôde continuar o tratamento por completo. No tocante às predisposições raciais das cardiopatias, os cães de grande porte são menos propensos a desenvolver a doença valvar crônica de mitral. Entretanto, quando ocorrem repercussões hemodinâmicas, elas tendem a ser mais agressivas nestes animais. Além disso, a ocorrência de coágulos secundários à estase sanguínea incide frequentemente nos gatos e é rara nos cães. Contudo, o exame ecocardiográfico permitiu o estabelecimento do diagnóstico e influenciou diretamente o tratamento e o prognóstico do caso. Portanto, ressalta-se que apesar de pouco frequente, a doença valvar crônica de mitral pode acometer os cães de grande porte e que esta condição pode predispor a formação de coágulos e tromboembolismo.

Palavras-chave: Endocardiose de mitral. Cardiopatia. Ecocardiografia. Cardiologia veterinária.

\section{ESTRESSE OXIDATIVO SISTÊMICO EM CÃES COM HIPERLEPTINEMIA}

Systemic oxidative stress in dogs with hyperleptinemia

BOSCO, A. M.; ALMEIDA, B. F. M.; VALADARES, T. C.; PEREIRA, A. A. F.; BAPTISTIOLLI, L.; HOFFMANN, D. J.; CIARLINI, P. C.

Resumo: A obesidade é a doença nutricional mais encontrada na espécie canina e sua incidência vem crescendo muito rapidamente. A leptina é uma proteína sintetizada principalmente por adipócitos e correlaciona-se positivamente com o escore de condição corporal em cães. Um dos efeitos adversos da hiperleptinemia em humanos inclui o estresse oxidativo. No entanto, na espécie canina, a provável relação entre esta condição e o estresse oxidativo ainda não foi estabelecida. Neste sentido, foi investigada a hipótese de que o estresse oxidativo sistêmico ocorre em cães com hiperleptinemia. De acordo com o escore de condição corporal (ECC), foram selecionados 76 cães adultos, com grupo controle formado por 24 cães com ECC 4-5, grupo sobrepeso por 25 cães com ECC 6-7 e grupo obeso por 27 cães com ECC 8-9. Foram formados mais dois subgrupos: cães com hiperleptinemia e sem hiperleptinemia, agrupados conforme o intervalo confiança de $95 \%$ obtido dos valores de leptina plasmática do grupo controle. De todos os cães selecionados, foi mensurada a leptina plasmática e os marcadores de estresse oxidativo sistêmico como peroxidação lipídica, capacidade antioxidante total (TAC), concentração oxidante total (TOC) e o índice de estresse oxidativo (IEO). Os cães do grupo obeso apresentaram maior concentração plasmática de leptina em relação ao grupo controle $(27,45 \pm 27,72$ vs. $9,79 \pm 6,62 \mathrm{ng} / \mathrm{mL}, \mathrm{p}=0,0144$, teste Kruskal-Wallis com o pós-teste de Dunn), sendo que a hiperleptinemia (>13,09 ng/mL) ocorreu em 44,44\% dos cães com sobrepeso e em $73,7 \%$ dos cães obesos. 
Cães com hiperleptinemia apresentaram maior TOC $(97,16 \pm 45,49$ vs. $155,7 \pm 64,92 \mu \mathrm{mol} / \mathrm{L}, \mathrm{p}=0,0070$, teste Mann Whitney), IEO (11,24 $\pm 5,27$ vs. $20,23 \pm 12,19 \%$, $\mathrm{p}=0,0114$, teste $\mathrm{t}$ não pareado) e peroxidação lipídica $(6,08 \pm 3,63$ vs. $10,13 \pm 5,57 \mu \mathrm{mol} / \mathrm{L}, \mathrm{p}=0,0228$, teste Mann Whitney). Quando comparado ao controle, no entanto, não houve alteração da TAC (o,89 \pm o,20 vs. $0,87 \pm 0,19 \mathrm{mmol} / \mathrm{L}, \mathrm{p}=0,8170$, teste $\mathrm{t}$ não pareado) Semelhante a outros estudos realizados na espécie canina, os resultados deste trabalho indicaram que o grupo obeso foi o que apresentou maior concentração plasmática da leptina. Assim, a hiperleptinemia parece contribuir para o quadro de estresse oxidativo em cães. Em humanos, já se sabe que ela está correlacionada com o aumento da peroxidação lipídica, sendo recentemente observado que o estresse oxidativo é mediado pela ativação da NADPH oxidase em indivíduos com hiperleptinemia.

Palavras-chave: Obesidade. Canina. Leptina. Antioxidante.

\section{ADMINISTRAÇÃO DE DOXICICLINA PARA TRATAMENTO DE HEMOPARASITOSE DURANTE A GESTAÇÃO DE CADELAS: RELATO DE CASO}

Case report about doxycycline administration for hemoparasitosis treatment during pregnancy in bitches

ALVES, B. M. S. M.; ALVES, I. P.; FERRARINI, J. C. M.; FARIA, M. C.; RAMOS, P. H. O.; KOIVISTO, M. B.

Resumo: A doxiciclina é um antimicrobiano utilizado para tratamento de alguns tipos de hemoparasitoses em cães, porém a sua administração é contraindicada para gestantes, devido aos efeitos adversos, como deformidades ósseas, toxicidade hepática e renal, relacionada à capacidade do fármaco atravessar a barreira placentária. Além disso, seus efeitos são agravados no início da gestação, devido à organogênese e desenvolvimento ósseo, podendo inclusive causar morte e reabsorção embrionária ou abortamentos. Foram atendidas, no hospital veterinário da Faculdade de Medicina Veterinária da Universidade Estadual Paulista (FMV-Unesp Araçatuba), quatro cadelas, jovens (de um a cinco anos) no início de gestação (aproximadamente até 30 dias, diagnosticados pela ultrassonografia), demonstrando sintomas semelhantes, como: febre, hiporexia, êmese e apatia. Os hemogramas apresentaram trombocitopenia e em alguns casos, anemia. O quadro clínico, em consonância ao resultado do hemograma sugeriu diagnóstico de hemoparasitose. $\mathrm{O}$ tratamento escolhido foi doxiciclina em doses entre $5 \mathrm{mg} / \mathrm{kg}$ e $6,5 \mathrm{mg} / \mathrm{kg}$, associado ao dipropionato de imidocarb em dose de $6,6 \mathrm{mg} / \mathrm{kg}$; os proprietários foram instruídos dos possíveis riscos do tratamento. Após alguns dias, duas fêmeas retornaram relatando melhora dos sintomas, mas com a presença de secreção vaginal avermelhada ou amarronzada. A ultrassonografia foi repetida e foi constatada reabsorção fetal. As duas outras cadelas foram acompanhadas até o final da gestação com melhora dos sintomas devido ao tratamento. Uma destas fêmeas pariu dois filhotes, dos quais um natimorto, por conta das dificuldades no parto. A outra cadela pariu por parto eutócico, cinco neonatos saudáveis. Alguns destes últimos foram acompanhados até a idade adulta permanecendo saudáveis, sem a observação de malformações ou anomalias. Dentre os parasitas sanguíneos mais comuns dos cães estão a Erliquia spp. e Babesia spp. ambos transmitidos pela picada de carrapato ixodídeo. Em cães, estes parasitas podem causar sinais e alterações típicas idênticas às descritas neste relato, além de linfadenomegalia, esplenomegalia e sinais multissistêmicos associados à dificuldade de contenção de hemorragias pela trombocitopenia. Durante a gestação, esta afecção pode causar danos tanto à saúde materna quanto à fetal e o diagnóstico e tratamento são de extrema importância para manutenção da gestação. Assim, a conclusão obtida foi que os prejuízos associados à evolução das hemoparasitoses superam os riscos advindos da instituição do tratamento com doxiciclina.

Palavras-chave: Gestação. Cadelas. Doxiciclina. Hemoparasitose. Reabsorção fetal.

\section{ANESTESIA MULTIMODAL PARA ARTRODESE TIBIOTÁRSICA E REDUÇÃO ABERTA DE LUXAÇÃO COXOFEMORAL EM RAPOSA DO CAMPO (LYCALOPEX VETULUS): RELATO DE CASO}

Multimodal anesthesia for tibio-tastic arthrodesis and open reduction of coxofemoral luxation in field fox (Lycalopex vetulus): a case report

SIQUEIRA, C. E.; OLIVEIRA, S. P.; SILVEIRA, B. C. R.; ENEAS, M. D.; MIYASHIRO, V. Y.; CARVALHO, J. R.; BRUNO, D. B.; EUGÊNIO, F. R.; SANTOS, P. S. P.

Resumo: A raposa do campo, espécie vulnerável em risco de extinção, apresentou uma redução de sua população de cerca de 30\% nos últimos 15 anos. Neste sentido, 
as técnicas anestésicas multimodais, que empregam diferentes fármacos visando maior eficiência e segurança anestésica com menor depressão cardiorrespiratória, são determinantes para o sucesso cirúrgico, principalmente em espécies pouco estudadas. Uma raposa do campo, macho, adulto, 3,3 $\mathrm{kg}$ foi atendida no hospital veterinário da Faculdade de Medicina Veterinária da Universidade Estadual Paulista (FMV-Unesp Araçatuba) com histórico de atropelamento. No exame clínico foi observado estado de consciência alerta, temperatura (T) de $35,8^{\circ} \mathrm{C}$, pulso forte e mucosas normocoradas. No exame radiográfico do membro pélvico esquerdo foi observada luxação coxofemoral e tibiotársica. No dia 25 de junho de 2017 o animal foi submetido a uma cirurgia para a realização de artrodese tibiotársica e redução aberta de luxação coxofemoral. O paciente encontrava-se alerta, porém agressivo, o que não permitiu a realização do exame físico. Nos exames laboratoriais, foram encontrados discreta leucocitose e aumento da enzima ALT. A medicação pré-anestésica foi realizada com telazol $10 \%$ (6 mg/kg) e morfina $1 \%(0,6 \mathrm{mg} / \mathrm{kg})$, IM, contudo, houve a necessidade da reaplicação de telazol $10 \%(4 \mathrm{mg} / \mathrm{kg})$ para obtenção de acesso venoso e indução anestésica, realizada com propofol $1 \%(3 \mathrm{mg} / \mathrm{kg})$ e midazolam $0,5 \%(0,1 \mathrm{mg} / \mathrm{kg})$. Como ato contínuo, o animal foi intubado e mantido anestesiado com isofluorano. A técnica anestésica regional efetuada consistiu no bloqueio peridural lombossacro (L7-S1) com levobupivacaína $0,75 \%(1 \mathrm{mg} / \mathrm{kg})$ e fentanil $(5 \mu \mathrm{g} / \mathrm{kg})$. Durante o procedimento anestésico foram avaliados: frequência cardíaca (FC), frequência respiratória $(f)$, saturação de oxi-hemoglobina $\left(\mathrm{SpO}_{2}\right)$, dióxido de carbono ao final da expiração (ETCO $)$, pressão arterial sistólica, diastólica e média (PAS, PAD e PAM), temperatura (T) e concentração anestésica expiradas (Etiso V\%). No início do procedimento o animal apresentou hipotensão, o que determinou a administração de solução hipertônica com $\mathrm{NaCl} 7 \%$ (2 mL/kg), IV e redução da concentração anestésica inspirada, com valores restabelecidos e dentro da normalidade após 10 minutos. Os parâmetros avaliados mantiveram-se dentro dos valores de referência, com apenas redução gradual da temperatura ao longo do procedimento. No pós-operatório imediato foi utilizado tramadol 5\% (5 mg/kg, IM), dipirona ( $25 \mathrm{mg} / \mathrm{kg}$, SC) e meloxicam (o,1 mg/kg, SC) como terapia analgésica. A recuperação anestésica foi prolongada, a raposa foi aquecida (até atingir valores superiores a $36,5^{\circ} \mathrm{C}$ ) e a hipoglicemia $(33 \mathrm{mg} / \mathrm{dL})$ tratada com bolus de glicose $50 \%(0,5 \mathrm{~mL} / \mathrm{kg})$. O protocolo anestésico, associado ao bloqueio regional foram eficientes e seguros para os procedimentos cirúrgicos realizados no animal.

Palavras-chave: Osteossíntese. Contenção química. Anestesia balanceada.

08. CORRELAÇÃO ENTRE AS PRESSÕES ARTERIAIS MÉDIAS OBTIDAS NA ARTÉRIA METATÁRSICA DORSAL E NA ARTÉRIA AURICULAR CAUDAL DE CÃES SUBMETIDOS A PROCEDIMENTOS CIRÚRGICOS JUNTO AO HOSPITAL VETERINÁRIO LUIZ QUINTILIANO DE OLIVEIRA (FMV-UNESP ARAÇATUBA): ESTUDO RETROSPECTIVO

Correlation between the medium arterial pressures obtained in the dorsal metatarsic artery and the caudal auricular of dogs submitted to surgical procedures on the veterinary hospital Luiz Quintiliano de Oliveira (FMV-Unesp Araçatuba): retrospective study

SIQUEIRA, C. E.; SILVEIRA, B. C. R.; OLIVEIRA, S. P.; CARVALHO, J. R.; SANTOS, P. S. P.; DALMAGRO, T. L.; FLORIANO, B. P.; MATSUBARA, L. M.

Resumo: A pressão arterial é uma boa indicadora da profundidade anestésica, e o conhecimento de seus valores é de extrema importância para avaliação da hemodinâmica do animal. A pressão arterial invasiva apresenta vantagens sobre os métodos indiretos, apresentando valores mais fidedignos e colheita contínua de registros. Nesse contexto, este trabalho analisou a correlação entre os valores da pressão arterial média (PAM) entre a artéria metatársica dorsal e auricular caudal em cães submetidos a anestesia inalatória. Foram avaliadas fichas anestésicas de 30 cães, pesando em média 14,8 kg $( \pm 9,7)$ submetidos a diferentes procedimentos cirúrgicos e anestésicos, no período de março a dezembro de 2016, no Hospital Veterinário Luiz Quintiliano de Oliveira, da Faculdade de Medicina Veterinária da Universidade Estadual Paulista (FMV-Unesp Araçatuba). O estudo foi realizado com fichas anestésicas padronizadas com a PAM da artéria metatársica dorsal e auricular caudal. Foram utilizados cateteres de mesmo calibre conectados a linhas de pressão de mesmo comprimento e diâmetro, preenchidos com solução heparinizada e conectados a transdutores. O ajuste da altura, em relação ao solo, dos transdutores foi determinado por meio da altura do coração do cão. Os valores das pressões foram exibidos simultaneamente por um monitor multiparamétrico, 
após a cateterização de ambas as artérias. O estudo foi dividido em sete momentos com intervalos de 10 minutos (Mo, M10, M20, M30, M40, M50 e M6o). Os dados foram submetidos à análise estatística utilizando-se o teste de Shapiro-Wilk, porém devido à elevada variância observada foi necessária conversão em Log. Após testes paramétricos para comparações, foi calculada a correlação de Spearman. Os valores da PAM das artérias metatársica dorsal e auricular caudal, coletados como medidas únicas, diferiram estatisticamente no Mo $(65 \pm 17,2$ e $58 \pm 17,3)$, respectivamente. Os valores da PAM da artéria metatársica apresentaram forte correlação $(r>0,7)$ com os colhidos por meio da cateterização da artéria auricular caudal em todos os momentos. Apesar de não ser observada diferença estatística, houve variação entre os valores obtidos em ambas artérias. A artéria auricular caudal apresentou valores inferiores à metatársica dorsal, que devem ser considerados para não ocorrer a determinação errônea de hipotensão. A artéria auricular caudal pode ser utilizada como alternativa à metatársica dorsal para obtenção da PAM.

Palavras-chave: Caninos. Artéria. Pressão arterial.

\section{ANTICORPOS IGG ANTIVÍRUS DA RAIVA EM INDIVÍDUOS COM POTENCIAL RISCO DE EXPOSIÇÃO AO VÍRUS DA DOENÇA}

Anti-rabies IGG antibodies in persons at risk of exposure to rabies virus

ALVES, C. C.; NAGATA, W. B.; QUEIROZ, L. H.; NUNES, C. $M$.

Resumo: A raiva é uma doença negligenciada que atinge 150 países em todo o mundo. A profilaxia antirrábica pré-exposição (PPE) é a medida indicada para indivíduos expostos a maior risco de infecção. Desde 1993, a Faculdade de Medicina Veterinária da Universidade Estadual Paulista (FMV-Unesp Araçatuba) promove a vacinação antirrábica, em esquema $\mathrm{PPE}$, dos estudantes ingressantes, seguida de avaliação sorológica anual. A conduta, além de atender o objetivo de promover a prevenção da raiva em um grupo com particular risco de infecção, também faz com que os futuros profissionais adquiram o hábito de avaliarem anualmente seus respectivos níveis de proteção contra a raiva. Este trabalho é um estudo retrospectivo quali-quantitativo, realizado pelo levantamento dos registros dos arquivos do Serviço de Vigilância Epidemiológica da Secretaria de
Saúde da Prefeitura Municipal de Araçatuba, no período compreendido entre os anos de 2000 a 2016. Dos 3.010 registros realizados no período, $84,7 \%$ apresentaram título de anticorpos considerados como protetores contra o vírus da raiva $(\geq 0,5 \mathrm{UI} / \mathrm{mL})$. Os registros incluem 1.427 indivíduos que realizaram números variáveis de titulações de anticorpos (IgG) contra o vírus da raiva em anos sucessivos. Em 709 (49,7\%) indivíduos com uma única titulação houve $84,1 \%$ de proteção; em 281 $(19,7 \%)$ com duas titulações, $96,4 \%$ de proteção; em 186 (13\%) com três titulações, 62,9\% de proteção; em 157 (11\%) com quatro titulações, 56,7\% de proteção; e em 61 (4,3\%) com cinco titulações, 53,2\% de proteção. Constata-se, portanto, que a resposta imune protetora foi de quase $100 \%$ quando os indivíduos receberam duas doses de vacina, sendo decrescente a partir desta. A avaliação individual da dinâmica de anticorpos a ser realizada deverá detalhar melhor tais resultados. Além disto, pode-se inferir que a avaliação anual da resposta imune apresenta tendência bastante decrescente ao longo dos cinco anos, período em que os estudantes estão cursando a graduação, o que sugere a dificuldade no estabelecimento do hábito da realização anual sistemática de tal procedimento. Este trabalho constatou que a imunização antirrábica realizada em esquema PPE pode desencadear, de maneira eficiente, a resposta imune protetora contra o vírus da raiva, aparentemente já na segunda dose da vacinação.

Palavras-chave: Lyssavirus. Vacina antirrábica. Pré-exposição.

\section{LEVANTAMENTO DE CASOS DE PITIOSE CUTÂNEA EQUINA NO HOSPITAL VETERINÁRIO DA FMV-UNESP ARAÇATUBA (1994-2017)}

Case survey of equine cutaneous pythosis at the veterinary hospital of the FMV-Unesp Araçatuba (1994-2017)

DENADAI, D. S.; FARIA, A. P. P. A.; ROSADO, R. S.; BARBOSA, S. O.; DONADON, A. E. S.; BORGES, A. S.; ALVEZ, A. L. G.; RODRIGUES, C. A.; LUVIZOTTO, M. C. R.; LUCAS, F. A.; PEIRÓ, J. R.

Resumo: A pitiose é uma zoonose causada pelo oomiceto Pythium insidiosum, que atinge equinos, caninos, bovinos, ovinos, felinos, peixes e humanos. Ocorre em áreas tropicais, subtropicais e temperadas, requerendo temperaturas ambientais situadas entre 30 
e $40^{\circ} \mathrm{C}$ e acúmulo de água (pântanos e lagoas) para seu desenvolvimento. As lesões observadas na pitiose são grandes massas teciduais, granulomatosas, ulceradas, com bordas irregulares e hifas recobertas por células necróticas, originando massas branco-amareladas irregulares (2 a $10 \mathrm{~mm}$ ) chamadas de kunkers, podendo apresentar secreção serosanguinolenta, mucosanguinolenta, hemorrágica e às vezes mucopurulenta. Este trabalho é um levantamento retrospectivo dos casos de pitiose cutânea equina atendidos no hospital veterinário da Faculdade de Medicina Veterinária da Universidade Estadual Paulista (FMV-Unesp Araçatuba), no período compreendido entre janeiro de 1994 a setembro de 2017. Os registros levantados revelaram a confirmação de 53 casos de equinos com pitiose, (média de 2,2 casos/ano), com predomínio de fêmeas (64\%). Todos os casos tiveram diagnóstico citológico ou histopatológico positivo. O maior número de casos foi observado durante ou após a estação chuvosa, que corresponde ao primeiro semestre do ano, destacando-se os meses de abril ( 15 casos) e maio (sete casos), correspondendo a $41,5 \%$ dos casos. As localizações predominantes foram as extremidades distais dos membros e a porção ventral tóraco-abdominal, áreas em que há maior contato com água contaminada por zoósporos, contudo, um animal apresentou pitiose na face e outro no úbere. O tratamento preconizado foi a exérese cirúrgica associada à administração oral de iodeto de potássio $(67 \mathrm{mg} / \mathrm{kg})$, SID, durante 30 a 45 dias. Dentre os animais tratados, 45 foram considerados curados e receberam alta, apresentando média de 69 dias de internamento. Em um animal não foi realizado o tratamento completo, dois vieram à óbito e cinco foram eutanasiados devido ao caráter refratário da lesão. Do total de casos atendidos no setor da clínica cirúrgica de grandes animais, a pitiose cutânea representou $1,5 \%$ da casuística, um número pequeno, considerando todas as demais enfermidades que acometeram os equinos. Todavia, pode-se afirmar que a pitiose está presente na região de Araçatuba/ SP e necessita de maior atenção, tanto por parte dos proprietários dos animais como pelos médicos-veterinários, pois causa prejuízos significativos na criação de equinos no Brasil, seja pela morte dos animais, pelos gastos com tratamento, e pelo caráter zoonótico, muitas vezes desconhecido por grande parte da população e negligenciado pelos sistemas de saúde.

Palavras-chave: Cavalos. Dermatopatia. Oomiceto. Pythium insidiosum. Zoonose.

\section{ULTRAFILTRAÇÃO PARA A RECUPERAÇÃO DE PROTEÍNAS DAS ÁGUAS DE LAVAGEM DO SURIMI}

Ultrafitration for the recovery of proteins from surimi wash water

OLIVEIRA, D. L.; GRASSI, T. L. M.; PAIVA, N. M.; PIRES, H. A.; SANTANA, B. N.; NAKAMURA, A. A.; PONSANO, E. H. G.

Resumo: O surimi é um concentrado de proteínas miofibrilares obtido de resíduos sólidos oriundos da industrialização do pescado ou a partir de pescado sem interesse comercial, que são lavados e estabilizados com crioprotetores. No processo de produção do surimi, grande quantidade de água é utilizada nas operações de lavagens, gerando um extenso volume de águas residuais ricas em matéria orgânica que, ao serem inadequadamente descartadas, causarão sérios problemas ambientais. As águas de lavagem do surumi apresentam de 0,5 a 2,3\% de proteínas, o que desperta o interesse em sua recuperação, de modo a reduzir o impacto ambiental. Este trabalho avaliou a eficiência do processo de ultrafiltração (UF) na recuperação das proteínas e no tratamento despoluente das águas de lavagem provenientes da elaboração do surimi. As águas de lavagem foram submetidas à UF em membrana de polietersulfona de $30 \mathrm{kDa}$, modelo FE10-FC-FUSo382, com área de $5,0 \mathrm{~m}^{2}$, à temperatura ambiente $\left(29^{\circ} \mathrm{C}\right)$, sob fluxo de líquido e tempo de operação determinados previamente, de forma a minimizar o entupimento da membrana. Amostras das águas de lavagem do surimi não filtradas (original) e após a UF (permeado e retentado) foram destinadas às determinações de $\mathrm{pH}$, sólidos totais (ST) e solúveis (SS), proteínas totais e óleos e graxas. A demanda química de oxigênio (DQO) foi determinada apenas nas águas originais e no permeado. Os SS, as proteínas e a DQO do permeado apresentaram uma redução significativa $(63 \%, 93 \%$ e $87 \%$, $\mathrm{p}<0,05$ ), indicando que a UF foi eficiente na remoção da carga orgânica da água gerada durante a fabricação do surimi, minimizando, assim, problemas ambientais no momento do descarte. A maior concentração de proteína foi encontrada no retentado $(37,66 \mu \mathrm{g} / 10 \mu \mathrm{l})$, mostrando que a UF foi capaz de recuperar as proteínas perdidas durante o processo de lavagem. As proteínas recuperadas representam um coproduto do processo de industrialização do pescado e podem ser usadas 
como ingrediente proteico na fortificação de formulações alimentícias. Assim, a UF foi viável tanto para a recuperação das proteínas quanto para a despoluição da água de lavagem do surumi, contribuindo para a sustentabilidade do setor produtivo do pescado.

Palavras-chave: Coprodutos. Demanda química de oxigênio. Filtração por membrana.

\section{SARNA PSORÓPTICA EM COELHO (ORYCTOLAGUS CUNICULUS)}

Psoroptic scabies in rabbit (Oryctolagus cuniculus)

\author{
BRUNO, D. B.; LORENA, L. L. G.; GARCIA, S. D.
}

Resumo: Os ácaros são ectoparasitas comumente encontrados na rotina clínica de lagomorfos. Devido a situações de comprometimento imunológico, os lagomorfos podem ser acometidos por diversas espécies de ácaros. Este resumo relata o caso de sarna em coelho, causada por Psoroptes cuniculi. Foi atendido no Hospital Veterinário Luiz Quintiliano de Oliveira, no setor de Clínica Médica de Animais Silvestres, uma coelha fêmea adulta, que foi encontrada em situação de abandono. No exame clínico constou: $2,1 \mathrm{~kg}$ de peso, parâmetros clínicos gerais sem alterações, e presença de material crostoso em grande quantidade aderido ao nariz (cerca de $4 \mathrm{~cm}$ ) e de maneira difusa em ambas as orelhas. $\mathrm{O}$ animal foi contido fisicamente para realização de raspado cutâneo e coleta de material para pesquisa microbiológica de fungos. $\mathrm{Na}$ análise microscópica do raspado de pele, foi constatada a presença de ácaros, identificados como Psoroptes cuniculi. A cultura fúngica resultou em Rhizopus spp., sugerindo não ter associação direta com o quadro clínico do animal. O tratamento instituído foi a aplicação de ivermectina $(0,5 \mathrm{mg} / \mathrm{kg})$ no Do, com fluidoterapia constituída de ringer com lactato $(100 \mathrm{ml} / \mathrm{kg} / \mathrm{dia})$ e suplementação vitamínica com Bionew $^{\circledast}(0,2 \mathrm{mg} / \mathrm{kg})$. Os primeiros sinais de melhora do quadro foram observados no $\mathrm{D} 7$, com parcial eliminação das lesões crostosas das orelhas, e no D1o o desprendimento total da crosta presente na narina. No D15 foi novamente aplicado ivermectina, na mesma dosagem, com melhora significativa, e no D3o eliminação total das crostas e repilação nos locais de alopecia. O ácaro Psoroptes cuniculi, um parasita auricular que pode ser observado por meio de otoscópio, ou pelo exame microscópico, é o agente etiológico da sarna dos coelhos, que se apresenta com lesões crostosas e espessas dispostas na forma de folhetos, secas, de coloração cinzenta a castanhada. Acomete principalmente as orelhas externas do animal, mas em situações menos comuns e com infestações intensas também pode parasitar narina e membros. Os sinais clínicos são queda das orelhas e prurido intenso, evidenciado pelo coçar das orelhas com as patas e agitação da cabeça. O diagnóstico baseia-se na observação dos sinais clínicos e raspado de pele para confirmação da infestação pelo parasita. O tratamento consiste em aplicações subcutâneas de ivermectina (o,2$0,6 \mathrm{mg} / \mathrm{kg}$ ) podendo se repetir de duas à três vezes com intervalo de 15 dias, a critério do clínico, a partir da evolução e melhora das lesões.

Palavras-chave: Ácaro. Lagomorfo. Ivermectina.

\section{VIABILIDADE DE CÉLULAS MAC-T DESAFIADAS COM O EXTRATO DA FOLHA DA HYMENAEA MARTIANA}

Viability of challenged mac-t cells with the extract of Hymenaea martiana leaf

VIEIRA, D. S.; CARDOSO, T. C.; BARROS, M.; LIMA, M. C.; ALCINDO, J. F.; ARAÚJO JÚNIOR, E. C.; PEREIRA, M. A. A. J. S.; MARINHO, M.; COSTA, M. M.; FEITOSA, F. L. F.

Resumo: Diante da crescente resistência aos antimicrobianos apresentada pelos micro-organismos causadores de mastite, novas alternativas são necessárias para o tratamento das infecções das glândulas mamárias dos ruminantes. A Hymenaea martiana possui comprovada atividades antimicrobiana, anti-inflamatória e cicatrizante, porém não se tem o completo conhecimento de seus possíveis efeitos citotóxicos. Este trabalho avaliou a viabilidade de células tumorais alveolares da glândula mamária bovina (MAC-T) desafiadas com o extrato etanólico bruto das folhas da H. martiana. As células MAC-T, gentilmente cedidas pelo Laboratório de Doenças Bacterianas da Universidade Federal de Viçosa (LDBAC/UFV), foram cultivadas em placas de 96 poços de fundo plano em meio Eagle modificado por Dulbecco (DMEM), suplementado com $10 \%$ de soro fetal bovino, penicilina $(100 \mu \mathrm{g} / \mathrm{mL})$ e estreptomicina $(100 \mu \mathrm{g} / \mathrm{mL})$. As células foram incubadas a $37^{\circ} \mathrm{C} \operatorname{com} 5 \%$ de $\mathrm{CO}_{2}$ por $24 \mathrm{~h}$ até atingir o crescimento em $1,5 \times 10^{5}$ células/poço. O extrato etanólico bruto da $H$. martiana foi diluído no DMEM partindo da concentração estoque de $25.000 \mu \mathrm{g} /$ $\mathrm{mL}$ até a diluição de $97,65 \mu \mathrm{g} / \mathrm{mL}$, sendo então utilizado 
neste estudo nove diluições em triplicata, e $100 \mu \mathrm{l}$ de cada diluição por poço. Foram considerados controle os poços apenas com o meio de cultura. Após esse processo, as placas retornaram para a estufa por $24 \mathrm{~h}$, sendo realizado então o ensaio colorimétrico para a avaliação da atividade metabólica celular (MTT). À medida que a concentração aumentou foram observadas alterações macroscópicas, como formação de vacúolos, condensação do núcleo e formação de agregados celulares. Além disso, a função mitocondrial (MTT) acompanhou o reflexo macroscópico do extrato nas células. A função mitocondrial diminuiu à medida que a concentração do extrato aumentou e a viabilidade celular foi mantida em 99\% na diluição $1562,5 \mathrm{mg} / \mathrm{mL}$, diluição bactericida (in vitro), que poderá ser utilizada em testes in vivo. As alterações morfológicas nas células não foram homogêneas e essa diferença de atividade pode ter ocorrido devido à diferença de receptores da superfície celular, ou até mesmo a fase de desenvolvimento celular. Porém, novos estudos devem ser realizados para elucidar a ação dos componentes presentes no extrato, úteis para o tratamento de doenças da glândula mamária. Como em uma concentração intermediária da $H$. martiana houve boa viabilidade das células o extrato dessa planta poderá vir a ser uma alternativa para o tratamento de infecções da glândula mamária, pois contém substâncias como flavonoides, terpenoides e taninos, e foi pouco tóxico para as células MAC-T.

Palavras-chave: Células. Plantas. Medicamentos. Novos produtos. Mastite.

\section{OCORRÊNCIA DE CRYPTOSPORIDIUM} SPP. EM PSITACÍDEOS EXÓTICOS MANTIDOS EM CATIVEIRO NAS REGIÕES SUL E SUDESTE DO BRASIL: AVALIAÇÃO DE MÉTODOS DE DIAGNÓSTICO E CLASSIFICAÇÃO MOLECULAR

Prevalence of Cryptosporidium spp. in caged exotic psittacines from Brazil: evaluation of diagnostic methods and molecular characterization

FERRARI, E. D.; NAKAMURA, A. A.; NARDI, A. R. M.; SANTANA, B. N.; CAMARGO, V. S.; NAGATA, W. B.; BRESCIANI, K. D. S.; MEIRELES, M. V.

Resumo: Este trabalho investigou a ocorrência e os métodos de diagnóstico da infecção por Cryptosporidium spp. em psitacídeos exóticos de cativeiro provenientes das regiões Sul e Sudeste do Brasil. A purificação dos oocistos nas amostras fecais de 463 psitacídeos foi realizada por meio de centrífugo-flutuação em solução de Sheather. A análise microscópica foi efetuada com o emprego da coloração negativa de verde malaquita. A amplificação de um fragmento parcial do gene $18 \mathrm{~S}$ rRNA de Cryptosporidium spp. foi determinada com nested PCR, seguida de sequenciamento dos fragmentos amplificados (nPCR/S). As amostras também foram testadas por meio de PCR duplex em tempo real, visando-se amplificar um fragmento do gene $18 \mathrm{~S}$ rRNA de Cryptosporidium galli e Cryptosporidium genótipo III de aves. A ocorrência de Cryptosporidium spp. pela microscopia e nested PCR (nPCR) foi de 3,02\% (14/463) e 4,97\% (23/463), respectivamente. A nPCR/S apresentou 1,73\% (8/463) de positividade para Cryptosporidium genótipo III de aves, o,86\% (4/463) para Cryptosporidium parvum e $0,22 \%(1 / 463)$ para Cryptosporidium canis. A PCR duplex em tempo real apresentou p.o 9,50\% (44/463) de positividade para as criptosporidioses gástricas, dos quais $1,94 \%(9 / 463)$ para C. galli, $5,83 \%(27 / 463)$ para Cryptosporidium genótipo III de aves e 1,73\% (8/463) para infecções mistas. Não houve diferença estatística entre a positividade pela $\mathrm{nPCR}$ e microscopia $(\mathrm{p}=0,1237)$ e houve concordância justa entre elas (Kappa $=0,242)$. Diferença estatística significante ( $\mathrm{p}<\mathrm{0,0001)}$ e concordância justa $($ Kappa $=0,317)$ foram obtidas nas comparações entre nPCR e PCR duplex em tempo real. Conclui-se que a PCR duplex em tempo real é a melhor opção para o diagnóstico de criptosporidiose gástrica e que Cryptosporidium genótipo III de aves é o mais comum dentre as espécies/ genótipos de Cryptosporidium que acometem psitacídeos.

Palavras-chave: PCR. Psitaciformes. Microscopia.

\section{ESTUDO RETROSPECTIVO DE DISCOPATIA CERVICAL E TORACOLOMBAR EM CÃES}

Retrospective study of cervical and thoracolumbar disk disease in dogs

CAVALCANTI, F. B. P.; LARANJEIRA, M. G.; NAGATA, W. B.

Resumo: A discopatia é a disfunção neurológica mais frequente em cães de meia-idade, com predomínio racial em condrodistróficos. A degeneração do disco promove a compressão medular e a injúria cursa com hiperalgesia e déficit locomotor. A variabilidade clínica é determinada pela localização da lesão e pelo grau de lesão medular. $\mathrm{O}$ 
tratamento da discopatia pode ser clínico ou cirúrgico e a decisão de escolha terapêutica envolve o segmento medular acometido e a graduação da disfunção neurológica. Este trabalho realizou um estudo retrospectivo dos animais que receberam tratamento clínico com discopatia atendidos pelo Hospital Veterinário Luiz Quintiliano de Oliveira no período de 2004 a 2015, considerando as variáveis: sexo, raça, idade e grau de comprometimento neurológico. Foram selecionados prontuários de 17 cães com diagnóstico confirmado de discopatia. Foram excluídos cães soropositivos para leishmaniose e prontuários com informações incompletas sobre o diagnóstico e o tratamento. As raças condrodistróficas foram as mais acometidas (15/17), e a região toracolombar (13/17) foi a de maior incidência. A idade média foi de 7,06 anos $( \pm 3,06)$ e 14 animais eram fêmeas. O grau II de disfunção neurológica foi o mais observado (8/17) quando comparado aos graus mais severos: III (4/17), IV (3/17), V (2/17). O tratamento clínico instituído propiciou a melhora de completa a satisfatória em 14/17 (82\%) animais, resultado semelhante aos obtidos na literatura. Devido ao grau da lesão e à ausência de resposta ao tratamento clínico, quatro animais tiveram que ser submetidos ao tratamento cirúrgico e dois deles apresentaram melhora, nos outros dois houve persistência da dor e disfunção locomotora. O resultado satisfatório da intervenção cirúrgica foi relacionado à precocidade da sua realização. A conclusão obtida foi que os animais que apresentam graus leves de disfunção neurológica podem ser tratados de forma conservadora. O agravamento do quadro neurológico, bem como disfunções em graus mais elevados indicam a realização do tratamento cirúrgico.

Palavras-chave: Disco intervertebral. Disfunção. Terapia.

\section{TRATAMENTO DE FERIDA CUTÂNEA EM CÃO COM USO DA MEMBRANA DE NANOFIBRAS DE POLIIMEROS BIODEGRADÁVEIS: RELATO DE CASO}

Manegement of dog skin wounds with a nanofiber membrane of biodegradable polymers: case report

SETO, J. A.; CAVALCANTI, F. B. P.; LARANJEIRA, M. G.

Resumo: O tratamento de feridas com o uso de curativos de cobertura permite a fixação e proliferação tecidual de forma rápida e com maior conforto ao paciente. Novos materiais têm sido desenvolvidos para tal finalidade, e entre eles encontram-se as Membranas de Celulose Bacteriana (MCB). O emprego das MCB para a cobertura temporária de feridas tem sido um caminho na busca do curativo ideal com baixo índice de hipersensibilidade. Este trabalho relata o uso de um novo curativo de cobertura de hemicelulose desenvolvida pela Innovatecs ${ }^{\circledast}$, constituído por uma mistura de bactérias e levedura do chá verde aplicado ao tratamento de feridas extensas e com exposição do periósteo. Um cão, macho, adulto, foi atendido no Hospital Veterinário Luiz Quintiliano de Oliveira, da Faculdade de Medicina Veterinária da Universidade Estadual Paulista (FMV-Unesp Araçatuba). O animal havia sido atropelado e apresentava uma ferida lacerativa em membros pélvicos, com perda de pele extensa e profunda, com exposição do periósteo na face medial da tíbia direita, na face lateral da articulação tibiotársica esquerda, e na face medial de região torácica esquerda. No entanto, não houve resposta satisfatória ao tratamento inicial e houve a instalação de um processo infeccioso nas feridas. Optou-se, então, pelo de uso de curativo de cobertura a base de membrana de nanofibras de polímeros biodegradáveis - Nanoskin ${ }^{\oplus}$ sobre a ferida. No primeiro dia foi realizada antissepsia da ferida com água oxigenada e posterior recobrimento com Nanoskin ${ }^{\otimes}$, malha de polipropileno e fixação com atadura comum. Os curativos diários foram realizados com lavagem da ferida com cloreto de sódio a o,9\%, troca da membrana quando necessário, malha de polipropileno e atadura comum. Na reavaliação diária da ferida foi observada a presença de tecido de granulação após as primeiras 48 horas, com ausência de desvitalização e contaminação tecidual. Após 10 dias foi constatado o completo recobrimento do periósteo exposto com tecido de granulação em ambos os membros. A partir do terceiro dia de tratamento começou a ser observada a contração da ferida, e aos seis dias de tratamento foi registrada a diminuição de cerca de $50 \%$ da área lesionada. A evolução do tratamento foi satisfatória e ao término de três meses a ferida estava completamente cicatrizada com boa qualidade funcional e estética do tecido cutâneo. Assim, este relato confirma a efetividade do uso da Nanoskin ${ }^{\otimes}$ como curativo de cobertura na qualidade do processo cicatricial, principalmente no caso em que há exposição do periósteo e em que não há indicação da cicatrização por terceira intenção.

Palavras-chave: Nanofibra. Feridas. Curativos. Cicatrização. Tratamento. 
17. EXPERIÊNCIA CLIINICA COMO AVELOZ NO TRATAMENTO DE NEOPLASIAS CUTÂNEAS E SUBCUTÂNEAS: RELATO DE CASOS

Clinical trial with the aveloz in the treatment of cutaneous and subcutaneous neoplasms: case report

VISSANI, F. F.; ALCÂNTARA, B. M.; TUBONE, L. T.; PERES, M. L.; SETO, J. A.; ONDAERA, N. N.; EUGÊNIO, F. R.; LUCAS, F. A.; ANDRADE, A. L.

Resumo: A Euphorbia tirucalli, da família das Euphorbiaceae, conhecida como aveloz, é uma planta semelhante aos cactos, que pode crescer até 10 metros de altura. Ao ser cortada, ela libera um látex branco e cáustico que, em diversas culturas, tem sido utilizado como terapia alternativa para algumas doenças. Recentemente, seu uso em pacientes com câncer redundou em inúmeros relatos associados à cura da enfermidade, despertando o interesse na comunidade científica para realização de estudos mais aprofundados. Este trabalho relata seis casos nos quais houve administração do látex em pacientes com neoplasias cutâneas ou subcutâneas. Os animais foram atendidos no hospital veterinário da Faculdade de Medicina Veterinária da Universidade Estadual Paulista (FMV-Unesp Araçatuba) e receberam indicação terapêutica para o uso do aveloz. Os pacientes, caninos, eram portadores de neoplasias cutâneas (hemangiossarcoma, $\mathrm{n}=5$ ) e subcutânea (carcinoma de glândula perineal, $\mathrm{n}=1$ ), com idades situadas entre sete a 13 anos, cujas lesões eram nodulares variando entre $0,5 \mathrm{a} 2,0 \mathrm{~cm}$, aplanadas, exceto o carcinoma. Aos hemangiossarcomas, foi recomendada a diluição do produto - que foi manipulado na FMVA-Unesp, adotando critérios estabelecidos em literatura consultada - em óleo de girassol (6o gotas $+30 \mathrm{~mL}$ $\mathrm{DMSO}_{4}+30 \mathrm{~mL}$ óleo girassol) com aplicações sobre as lesões, uma vez ao dia. Para a lesão nodular subcutânea, optou-se pela administração única intralesional com o extrato de aveloz (10 gotas) diluído em água para injeção $(20 \mathrm{~mL})$. Quinzenalmente foi efetuada a avaliação da aparência clínica e da regressão das lesões. Houve regressão total dos hemangiossarcomas aos 30 dias, em média, e do carcinoma perineal em uma semana. O hemangiosarcoma e o carcinoma perineal são neoplasias frequentes em cães e possuem elevada taxa de manifestação cutânea. Ambos requerem excisão cirúrgica com ampla margem, associado à quimioterapia adjuvante e/ou à radioterapia. Dos cinco pacientes com hemangiossarcoma, quatro se encontravam no estádio clínico I (TNM), com nódulos em região ventral e acometimento dérmico. $\mathrm{O}$ outro paciente apresentava nódulos disseminados por tronco e membros, classificado no estádio clínico II. Ressalta-se o elevado poder metastático local de ambas as neoplasias e as baixas taxas de responsividade aos tratamentos adjuvantes indicados. Os resultados alcançados e o tempo de remissão das neoplasias indicaram que o aveloz possui efeitos antineoplásicos, e que pode ser uma alternativa terapêutica não invasiva para o tratamento das referidas neoplasias. Estudos adicionais deverão ser realizados para caracterizar os compostos fitoterápicos presentes na planta.

Palavras-chave: Cães. Hemangiossarcoma. Carcinoma perineal. Euphorbia tirucalli.

\section{NO, ROS E IL-17 APÓS O BLOQUEIO DE PD-1 EM LEUCÓCITOS ESPLÊNICOS NA LEISHMANIOSE VISCERAL CANINA}

NO, ROS and Il-17 after pd-1 blockade in spleen leukocytes in canine visceral leishmaniasis

REBECH, G. T.; BRAGATO, J. P.; COSTA, S. F.; VENTURIN, G. L.; MELO, L. M.; ITO, L. T. S.; LIMA, V. M. F.

Resumo: A molécula PD-1 (Programmed cell death 1) é altamente expressa nas células leucocitárias dos cães com leishmaniose visceral (LV) e seu envolvimento com a função microbicida ainda não foi caracterizado. Este trabalho avaliou o efeito do anticorpo bloqueador de PD-1 na produção de óxido nítrico (NO) de espécies reativas ao oxigênio (ROS), de interleucina 17 (IL-17) e na carga parasitária em cultura de leucócitos do baço de cães com LV. Foram utilizados 15 cães com LV, provenientes do centro de zoonoses de Araçatuba, e cinco cães saudáveis com três a cinco anos de idade, macho ou fêmea de diferentes raças e pesos. Os cães infectados apresentavam sinais clínicos compatíveis com leishmaniose visceral, de acordo com o teste rápido imunocromatográfico (DPP) e ELISA indireto positivos. Os leucócitos do baço dos cães saudáveis e infectados foram mantidos a $4^{\circ} \mathrm{C}$ em meio de cultura celular para determinação da porcentagem de expressão da proteína PD-1 por citometria de fluxo utilizando anticorpo monoclonal conjugado a PE (Antihuman CD279, BD Biosciences) e outra parte das células foi dispensada em placas de 24 poços (Costar) na presença ou ausência de fitohemaglutinina ( $1 \%$ do volume final), antígeno solúvel (AgSL) de Leishmania infantum (20 $\mu \mathrm{g} /$ $\mathrm{ml}$ ), anticorpo bloqueador de PD-1 (Anti-human CD279 
e Bioscience) $(5 \mu \mathrm{g} / \mathrm{ml})$, AgSL $(20 \mu \mathrm{g} / \mathrm{ml})$, isotipo controle (BD Biosciences) $(5 \mu \mathrm{g} / \mathrm{ml})$ e AgSL $(20 \mu \mathrm{g} / \mathrm{ml})$, em incubação a $37^{\circ} \mathrm{C}$ e $5 \%$ de $\mathrm{CO} 2$ por 20 horas para análise da concentração de NO e de ROS e por 72 horas para avaliação da IL-17 no sobrenadante de cultura e da carga parasitária. O NO e o ROS foram avaliados com sondas comerciais (Invitrogen-Leiden), seguindo as instruções do fabricante. A IL-17 foi avaliada no sobrenadante, com kit de ELISA DuoSet (R\&D Systems) seguindo as instruções do fabricante. A carga parasitária foi avaliada por microscopia de luz pela contagem de parasitas em macrófagos infectados e por citometria de fluxo com os anticorpos: monoclonal anti gp63 (ABD, Serotec), goat anti-Mouse IgG2a (Thermo Fisher Scientific) conjugado à ficoeritrina e anticorpo monoclonal Anti-F4/8o (Abcam) conjugado a isotiocianato de fluoresceína. Os resultados foram analisados com nível de significância de $\mathrm{p}<0,05$. Os cães infectados apresentaram aumento da porcentagem de expressão do PD-1. Os níveis de NO e ROS nos leucócitos esplênicos dos cães infectados aumentaram após o bloqueio do receptor de PD-1, enquanto a IL-17 e a carga parasitária diminuíram. Os resultados obtidos sugeriram que o bloqueio do receptor PD-1 melhora a capacidade microbicida do hospedeiro, reduzindo a carga parasitária.

Palavras-chave: Células esplênicas. Citocinas. Protozoário CD279.

\section{ANÁLISE IN SILICO DA FUNÇÃO DE MICRORNAS E GENES DIFERENCIALMENTE EXPRESSOS NA INFECÇÃO POR TUBERCULOSE}

In silico functional analysis of differentially expressed microRNAs in tuberculosis

FERREIRA, G. C.; GARCIA, L. E.; LOPES, F. L.

Resumo: MicroRNAs são pequenas moléculas de RNAs não-codantes que variam em tamanho de 20 a 22 nucleotídeos e que desempenham importante papel na regulação pós-transcricional de RNAs codantes. O gênero Mycobacterium possui agentes patogênicos como M. tuberculosis e $M$. leprae, que são os agentes etiológicos importantes em seres humanos. Este trabalho avaliou in silico os miRNAs, e genes alvos, que são diferencialmente expressos na infecção patogênica intracelular de Mycobacterium tuberculosis no hospedeiro humano. Para tanto, foi realizada uma pesquisa de dados (2011-2017) no Pubmed-NCBI.
Foi utilizada uma combinação de vocabulário controlado de interesse para realização das buscas. Os dados foram extraídos do texto, tabelas e figuras dos estudos para serem o mais inclusivo possível e, aos miRNAs detectados, foi atribuído um valor mínimo para ofold change acima de 2 e abaixo de -2. Os alvos putativos (RNAm) de diferentes conjuntos de miRNAs foram determinados com o emprego do programa TargetScan (http://www.targetscan.org). Foi elaborado um diagrama tabular de Venn com o emprego do recurso FunRich (http://www.funrich.org/) para a análise dos miRNAs comuns que estavam mais abundantes em vários artigos, e a relação desses genes-alvo em interações de redes foi investigada por análise de vias usando o programa Panther (http://pantherdb.org/). De um total de 116 artigos, nove foram selecionados por utilizarem técnicas de análise globais. Entre os artigos selecionados, sete miRNAs foram comuns a todos: miR-140-3p; miR-193a-3p; miR-142-5p (up-regulados); miR-107; miR-324-5p; miR-423-3p; e miR-361-5p (down-regulados). A partir dos miRNAs up-regulados foram encontrados 291 genes-alvo em comum a esses, e para os miRNAs down-regulados, 16 alvos em comum. Com a identificação dos genes-alvo, foi realizada a análise de enriquecimento funcional, obtendo vias biológicas potencialmente inibidas (miRNAs up-regulados), como ativação de células B e T, p53, angiogênese, inflamação mediada por citocinas e quimiocinas e vias de sinalização, como o fator de crescimento epidérmico (EGF). Com relação às vias potencialmente ativadas (miRNAs down-regulados) foram identificadas vias como a resposta de estresse oxidativo, sinalização Wnt (está associada à proliferação celular e à formação de tecidos) e vias metabólicas como biossíntese de metionina. A conclusão obtida foi que, apesar dos diferentes delineamentos experimentais dos estudos utilizados, várias vias biológicas em comum podem ser encontradas após a infecção por Mycobacterium, e que estes processos são regulados pós-transcricionalmente.

Palavras-chave: MicroRNA. Mycobacterium. Mineração de textos.

\section{ISOLADOS BACTERIANOS DE ÚLCERAS CORNEAIS DE CÃES E SUA RESISTÊNCIA BACTERIANA NA CIDADE DE ARAÇATUBA/SP}

Bacterial isolates from corneal ulcers of dogs and its bacterial resistance in the Araçatuba/SP city

TRUJILO, D. Y.; PEDROZA, T. M.; BENGUELLA, H.; ZANCHETTA, I. L.; BOTECA, A. M.; LORENA, L. L. G.; MARINHO, M.; ANDRADE, A. L. 
Resumo: Ceratites ulcerativas em cães são um importante problema em oftalmologia veterinária, que podem ocasionar a perda de visão, e quase sempre as bactérias da superfície ocular contribuem para isto. Portanto, o reconhecimento de tais bactérias é necessário, pois sua frequência e padrão de resistência antibiótica varia de acordo com a região e também com a sazonalidade. Pesquisas a respeito da identificação bacteriana e sua susceptibilidade são requeridas para direcionar o tratamento das soluções de continuidade na córnea. Este trabalho identificou as bactérias mais frequentes em úlceras corneais de cães atendidos no Hospital Veterinário Luiz Quintiliano Oliveira, da Faculdade de Medicina Veterinária da Universidade Estadual Paulista (FMV-Unesp Araçatuba), no período de janeiro/2016 a setembro/2017 e estabeleceu o perfil de resistência aos antibióticos comumente usados na rotina oftalmológica. O estudo incluiu 26 amostras de cães com diagnóstico clínico de úlcera de córnea. Com um swab estéril o material foi colhido diretamente das úlceras corneais dos animais, e semeado nos meios de cultura ágar sangue e ágar MacConkey, incubados em estufa bacteriológica a $37^{\circ} \mathrm{C}$ sob condições atmosféricas de aerobiose e microaerofilia, por um período de 24 a 48 horas. Os microrganismos foram identificados de acordo com as características morfotintoriais, bioquímicas e de cultivo. Os isolados foram submetidos à prova de sensibilidade microbiana pelo método de difusão com discos (CLSI/ NCCLS 2003), utilizando os principais antimicrobianos disponíveis e indicados na terapia oftalmológica, como: tobramicina, ampicilina, gentamicina, ciprofloxacina, neomicina, polimixa B e cloranfenicol. Foram identificados três principais gêneros de bactérias que corresponderam ao Staphylococcus spp. (65\%), Streptococcus spp. (20\%) e Pseudomonas spp. (15\%). Os resultados do antibiograma demostraram que o Staphylococcus spp. foi altamente sensível à polimixina $\mathrm{B}(85,71 \%)$ como também ao cloranfeni$\mathrm{col}(82,35 \%)$ e à ciprofloxacina $(50 \%)$. No entanto, mostrou-se resistente à neomicina (100\%), gentamicina $(62,5 \%)$, tobramicina (60\%) e ciprofloxacina (50\%). Estirpes de Streptococcus spp. foram significativamente sensíveis ao cloranfenicol $(71,42 \%)$ e resistentes à tobramicina e polimixina B (100\%), à gentamicina $(85,71 \%)$, neomicina e ciprofloxacina (66,66\%). Os isolados de Pseudomonas spp. foram sensíveis à ciprofloxacina e neomicina (100\%) e gentamicina (75\%); o perfil de resistência aqui encontrado permitiu inferir que as estirpes de Pseudomonas spp. são resistentes à tobramicina $(66,66 \%)$ e ao cloranfenicol (50\%). Os resultados obtidos indicam que Staphylococcus spp., Streptococcus spp. e Pseudomonas spp. são os três principais gêneros de bactérias em úlceras corneais de cães na região de Araçatuba, estado de São Paulo, Brasil, todos resistentes à tobramicina, porém sensíveis à ciprofloxacina, polimixina B e cloranfenicol.

Palavras-chave: Cães. Cultura. Antibiograma. Microbiota. Úlcera de córnea.

\section{HIPOSPADIA PERINEAL EM CÃO: RELATO DE CASO}

Perineal hypospadia in a dog: case report

COSTA, I. F.; COSTA, M. F.; LUVIZOTTO, M. C. R.

Resumo: A hipospadia é uma anomalia congênita do desenvolvimento da genitália externa, observada mais frequentemente em machos, cuja incidência é de 0,003\% na espécie canina. As raças descritas com maior frequência são pinscher, cocker spaniel, collie e doberman, porém o boston terrier é citado como geneticamente predisponente. A hipospadia é caracterizada por uma falha na fusão das pregas urogenitais, com desenvolvimento incompleto da uretra, devido à produção inadequada de andrógeno fetal. De acordo com a localização da abertura uretral externa, a hipospadia pode ser classificada como glandular, peniana, escrotal, perineal ou anal. Sua ocorrência pode estar associada ao criptorquidismo, anormalidades escrotais, pênis subdesenvolvido, intersexos, incontinência urinária e hérnia umbilical. $\mathrm{O}$ objetivo deste relato é descrever um caso de hipospadia perineal em um cão, macho, sem raça definida, com aproximadamente seis meses de idade, pesando $12 \mathrm{~kg}$, encontrado abandonado com suspeita de mutilação em região genital. $\mathrm{O}$ animal foi atendido na Clínica Veterinária Saúde Animal - Manduri/SP -, e no seu exame físico foi observado que a genitália externa era constituída de pênis vestigial com osso peniano rudimentar, porém sem orifício uretral e o prepúcio apresentava desenvolvimento incompleto; os testículos estavam localizados no subcutâneo da região inguinal bilateral, havendo ausência total da bolsa escrotal. A abertura uretral foi detectada na região ventral do ânus onde havia uma fina membrana que permitiu a passagem de sonda. O exame ultrassonográfico abdominal constatou presença de próstata rudimentar e inexistência de cornos uterinos e ovários. A pesquisa da possibilidade de intersexos foi realizada por cariotipagem, em $5 \mathrm{~mL}$ de sangue colhido por venopunção jugular, com seringa estéril contendo $0,5 \mathrm{ml}$ de heparina sódica. A amostra refrigerada foi encaminhada ao Departamento 
de Genética do Instituto de Biociências da Universidade Estadual Paulista em Botucatu/SP. Na cultura de linfócitos foram identificadas 20 células em metáfase com coloração convencional de Giemsa, as quais evidenciaram os cromossomos sexuais $\mathrm{X}$ e $\mathrm{Y}$ em $100 \%$ das células, indicando que o animal era cromossomicamente do sexo masculino, descartando-se a possibilidade de intersexualidade. Por tratar-se de hipospadia perineal, o animal foi submetido à orquiectomia bilateral. As características gonadais e sexuais secundárias observadas ao exame físico e de imagem deste relato não excluíam a possibilidade de intersexos, tornando-se imprescindível o exame de cariotipagem. Conclui-se que a avaliação clínica das alterações fenotípicas aliada à cariotipagem são de grande importância para o estabelecimento do diagnóstico da hipospadia.

Palavras-chave: Uretra. Anormalidade. Congênita. Cariotipagem.

\section{USO DE CORTICOTERAPIA MATERNA NA MATURAÇÃO DE FETOS FELINOS: RELATO DE CASO}

Use of antenatal maternal corticotherapy in feline fetuses maturation: case report

ALVES, I. P.; OLIVEIRA, P. R. H.; SILVA, F. E.; ALVES, B. M. S. M.; FARIA, M. C.; FERRARINI, J. C.; PINOTI, L. D. R.; KOIVISTO, M. B.

Resumo: A Síndrome de Angústia Respiratória é uma das condições patológicas de imaturidade fetal mais significativa, decorrente de deficiência na síntese de surfactante devido à imaturidade pulmonar. Diferentes fatores endocrinológicos, incluindo os glicocorticoides, possuem importante papel no desenvolvimento pulmonar fetal de várias espécies. Sabe-se que a administração antenatal de corticoides acelera o efeito dos glicocorticoides endógenos, aumentando a sobrevida neonatal em casos de parto prematuro. Foram atendidas no hospital veterinário da Faculdade de Medicina Veterinária da Universidade Estadual Paulista (FMV-Unesp Araçatuba) duas gatas sem raça definida, prenhes e com intensa dificuldade respiratória devido à hérnia diafragmática traumática. Ao exame clínico os parâmetros encontravam-se normais, com exceção da ausculta cardíaca que em ambas estava abafada. Ao exame ultrassonográfico foram confirmadas gestações com presença de fetos viáveis, evidenciando diferenciação córtico-medular renal e pelve renal não dilatada. O peristaltismo intestinal fetal apresentava-se discreto na paciente 1 e intenso na paciente 2 . O diâmetro biparietal sugeriu $55 \pm 3$ e $61 \pm 3$ dias de gestação nas pacientes 1 e 2, respectivamente. Considerando a organogênese fetal e que a gestação na gata tem duração média de 65 dias, podendo atingir 69, os fetos não se encontravam a termo. No exame radiográfico observou-se presença de dois fetos na paciente 1 e cinco fetos na paciente 2 e, em ambas, sinais radiográficos sugestivos de hérnia diafragmática. Devido à presença de hérnia e intensa dificuldade respiratória das gestantes, optou-se por realizar a herniorrafia. Considerando que o aumento dos níveis de cortisol materno no momento do parto é fundamental para a maturação pulmonar, por contribuir com a produção de surfactantes, nos dois casos foi administrado a betametasona $(0,5 \mathrm{mg} / \mathrm{kg})$ uma hora antes do procedimento cirúrgico, visando a aceleração da maturidade pulmonar. Foi realizada cesariana seguida pela redução e rafia de hérnia diafragmática. Após nascimento e reanimação neonatal, os recém-nascidos foram mantidos em incubadora a $32^{\circ} \mathrm{C}$. A vitalidade neonatal foi verificada com o emprego do sistema Apgar adaptado para neonatos caninos. Ao nascerem, os neonatos apresentavam-se bradicárdicos com respiração irregular e cianóticos. Com o passar do tempo houve a melhora nos parâmetros neonatais, atingindo escore Apgar 10 após 60 e 90 minutos (caso 1 e 2, respectivamente) de nascimento. Na Medicina Veterinária, especificamente em gatos, não há pesquisas em relação à influência da administração de glicocorticoides anteparto na mãe com o intuito de melhorar a vitalidade neonatal. Verificou-se que a administração materna de betametasona previamente à cesariana possivelmente contribuiu com a maturação pulmonar fetal, como observado em cadelas.

Palavras-chave: Maturação pulmonar. Cesariana. Vitalidade neonatal.

\section{COMPLEXO H IPERPLASIA ENDOMETRIAL CISTICA EM FELINOS: RELATO DE CASO}

Complex cystic endometrial hyperplasia in felinos: case report

FERRARINI, J. C. M.; FARIA, M. C.; ALVES, B. M. S. M.; OLIVEIRA, P. R. H.; ALVES, I. P.; KOIVISTO, M. B.

Resumo: O Complexo Hiperplasia Endometrial Cística - piometra -, é uma das afecções mais comumente diagnosticadas na clínica de pequenos animais. É o acúmulo de pus intrauterino que pode ser ocasionado por diversos fatores e que ainda não possui uma fisiopatogenia 
totalmente elucidada. Esta afecção ocorre com maior frequência em cadelas idosas ou de meia-idade, porém, também é descrita em gatas que receberam medicações contraceptivas, abortivas ou de indução de cio. Uma gata sem raça definida, não castrada, com queixa de aumento de volume abdominal há 20 dias e aquesia há uma semana foi atendida no hospital veterinário da Faculdade de Medicina Veterinária da Universidade Estadual Paulista (FMV-Unesp Araçatuba). O proprietário relatou que logo após a última gestação o animal recebeu medicação contraceptiva. Ao exame físico, o animal encontrava-se taquicárdico, taquipneico e aparentemente apático. A palpação abdominal foi impossibilitada devido à rigidez causada pelo aumento de volume abdominal. Ao exame ultrassonográfico o corno uterino direito media cerca de $4,89 \mathrm{~cm}$ de diâmetro e o esquerdo $6,19 \mathrm{~cm}$, ambos com parede fina e presença de severa quantidade de conteúdo intraluminal de moderada celularidade. No hemograma foi observado leucocitose por neutrofilia com desvio à esquerda. Diante dos exames complementares e da clínica do animal, foi realizado procedimento de ovariosalpingohisterectomia terapêutica. A peça cirúrgica (ovários e útero) pesou cerca de $1 \mathrm{~kg}$. Como tratamento pós-cirúrgico foi prescrito antibioticoterapia e analgesia, e marcado retorno após sete dias. $\mathrm{Na}$ ocasião do retorno, o animal apresentava todos os parâmetros dentro da normalidade. As medicações contraceptivas são análogos sintéticos de progestágenos e mimetizam os efeitos do corpo lúteo a fim de suprimir ou adiantar o estro. Essas drogas provocam efeitos secundários, como inibição da imunidade uterina e proliferação das glândulas do endométrio, ocasionando a formação da hiperplasia endometrial cística. Tais efeitos podem contribuir para o desenvolvimento da piometra e outras afecções que não se limitam ao ambiente uterino.

Palavras-chave: Felinos. Endometrial. Hiperplastia.

\section{LEISHMANIA INFANTUM REGULA A EXPRESSÃO DE MIRNAS EM CÃES COM LEISHMANIOSE VISCERAL E AFETA A CARGA PARASITÁRIA}

Leishmania infantum regulates miRNAs in dogs with visceral leishmaniasis and affects parasite load

BRAGATO, J. P.; MELO, L. M.; REBECH, G. T.; VENTURIN, G. L.; GARCIA, L. E.; LOPES, F. L.; LIMA, V. M. F.

Resumo: A Leishmaniose Visceral (LV) no homem é uma doença crônica e frequentemente fatal se não tratada. Os cães são potentes transmissores do parasito para humanos pelo vetor flebotomínio. A resposta imunológica dos indivíduos infectados por leishmanias pode ser modulada por microRNAs. Este trabalho foi delineado para avaliar os miRNAs diferentemente expressos em células mononucleares de sangue periférico (CMSP) de cães sintomáticos naturalmente infectados por Leishmania infantum $(\mathrm{n}=10)$ comparado os resultados obtidos com o grupo controle constituído por cães saudáveis $(n=5)$. No microarranjo, os miRNAs miR 21, miR 424, miR 194 e miR 451, houve um aumento de expressão na ordem de três vezes e os miRNAs miR 192, miR 503 e miR 371 tiveram um aumento de expressão na ordem de duas vezes. Os miRNAs miR 150 e miR 574 tiveram diminuição na expressão na ordem de duas vezes. A PCR em tempo real validou os resultados do microarranjo para os miRNAs miR 21, miR 150, miR 451, miR 192, miR 194 e miR 371. A carga parasitária das CMSP foi mensurada por PCR em tempo real, e correlacionada aos miRNAs, diferencialmente expressos. A carga parasitária mostrou correlação positiva forte com a expressão do miR 194, correlação positiva regular com a expressão do miR 371 e correlação negativa moderada com a expressão de miR 150. Foi realizada análise de alvos e vias no programa Ingenuity Pathway Analysis e 63 vias canônicas foram obtidas, dentre elas as vias sinalização de p53, papel antiproliferativo do TOB na sinalização de células T, $\mathrm{STAT}_{3}$, sinalização de receptor de morte e "crosstalk" entre células dendríticas e células natural killer (NK), que podem regular a resposta imune da LVC. A via "'crosstalk' entre células dendríticas e células NK" tem como alvos moléculas importantes envolvidas na imunopatogênese da Leishmaniose Visceral Canina (LVC), como NFkB, TNF- $\alpha$, CD8o, IFN- $\gamma$ e DNAM-1. Esses achados sugerem que os miRNAs interferem na resposta imunológica de cães infectados por L. infantum e sua correlação com a carga parasitária pode ajudar na identificação de alvos terapêuticos na LVC.

Palavras-chave: MicroRNAs. Leishmaniose visceral canina. Zoonose. Resposta imune.

\section{5. ÍNDICES PRODUTIVOS DE PROPRIEDADES LEITEIRAS DA MICRORREGIÃO DE BIRIGUI/SP, BRASIL}

Productive indices of dairy farms in Birigui, São Paulo state, Brazil

DELFINO, J. L. C.; GRASSI, T. L. M.; PONSANO, E. H. G.; NOGUEIRA, G. P. 
Resumo: Mais da metade do leite produzido no Brasil provém de propriedades com trabalho familiar (IBGE, 2006), o que denota importante papel socioeconômico. A assistência técnica oferecida aos produtores rurais precisa abordar aspectos que tratam de planejamento, organização, execução e controles. Este trabalho realizou, em 2016, uma amostragem por conveniência e, por meio de entrevista estruturada, com termo de consentimento, pesquisa em propriedades leiteiras $(\mathrm{n}=45)$ da microrregião de Birigui, estado de São Paulo, Brasil. O porte das propriedades foi definido pela produção de leite (PL) diária, de acordo com os critérios: pequeno $(\mathrm{n}=15)$ - até $100 \mathrm{~L}$; médio $(n=15)-101$ a $300 \mathrm{~L}$; grande $(\mathrm{n}=15)$ - mais de $300 \mathrm{~L}$. Os resultados obtidos (média \pm desvio padrão) foram: produtividade $6.274,9 \pm 4.981,4 \mathrm{~L} / \mathrm{ha} /$ ano, abaixo dos $7.300 \mathrm{~L} / \mathrm{ha}$ /ano relatados para rebanho mestiços em pasto de braquiária; o número de vacas em lactação (VL sobre o total de vacas) foi $71 \pm 14,2 \%$, próximo de $75 \%$, limite acima do qual o índice é considerado bom para produção de leite a pasto ou semiconfinamento; o intervalo entre partos (IEP) foi de 13,1 $\pm 1,3$ meses e a idade ao primeiro parto (IPP) de 33,2 $\pm 3,7$ meses. Os últimos dois parâmetros referidos aproximaram-se do considerado ideal, 12 meses para IEP (sendo 14 meses satisfatório para produção a pasto) e 30 a 32 meses para IPP para fêmeas mestiças. O número médio de vacas no rebanho foi $58,3 \pm 15,9 \%$ e $41,4 \pm 14$, $0 \%$ de VL no rebanho (VL sobre rebanho total). Os valores considerados ideais para estes índices são de 50\% e $42 \%$, respectivamente. A produção leiteira (PL) diária por VL foi de $10,9 \pm 4,8 \mathrm{~L}$, enquanto a PL por dia de IEP foi de 7,8 $\pm 3,9$ L. A PL por dia de IEP é o melhor índice para mensuração da eficiência da atividade leiteira, pois associa fatores produtivos e reprodutivos, sendo que o valor ideal para vacas mestiças é de $10 \mathrm{~kg}$ (como este trabalho foi feito por entrevistas, mensurar em litros ou quilogramas não gerou diferenças significantes). Em geral, as médias dos índices foram adequadas. Entretanto, a análise dos desvios padrões mostra que existiram propriedades com índices insatisfatórios. Nesse contexto, assistência técnica e extensão rural têm potencial para melhorar a produtividade de leite, concentrando suas atividades nas propriedades que apresentaram os piores índices.

Palavras-chave: Gado. Leite. Produtividade.
26. PERFIL DE PRODUTORES E SISTEMAS DE PRODUÇÃO DE LEITE NA MICRORREGIÃO DE BIRIGUI/SP, BRASIL

Milk producers's and dairy farms's profile in Birigui, São Paulo state, Brazil

DELFINO, J. L. C.; GRASSI, T. L. M.; PONSANO, E. H. G.; NOGUEIRA, G. P.

Resumo: Os sistemas brasileiros de produção de leite apresentam baixos índices de produtividade e qualidade. A assistência técnica e a extensão rural desempenham importante papel para a melhoria deste cenário. Este trabalho foi delineado para diagnosticar o perfil de uma amostra de produtores e sistemas de produção de leite. Foi realizada amostragem por conveniência $(n=45)$ de propriedades leiteiras da microrregião de Birigui/SP em 2016. Três estratos, com 15 propriedades cada, foram formados. Os estratos foram definidos de acordo com a produção de leite diária da propriedade, adotando os critérios estabelecidos: pequena (até 100 litros), média (de 101 a 300 litros) e grande (acima de 300 litros). A pesquisa foi conduzida por meio de entrevista estruturada, com termo de consentimento dos interessados. O tempo médio na atividade leiteira foi de 18,9 anos. Em $73,3 \%$ das propriedades o leite era a atividade principal. A assistência técnica era exclusivamente pública para 53,4\% das propriedades, particular para $22,2 \%$, enquanto $24,4 \%$ não recebiam esse tipo de serviço. Dos produtores, $73,3 \%$ desempenhavam outras atividades. O grau de escolaridade dos produtores foi distribuído em: $37,7 \%$ para ensino fundamental incompleto; $8,9 \%$ para ensino fundamental completo; $35,6 \%$ para ensino médio completo; e $17,8 \%$ para ensino superior completo. Em $77,8 \%$ das propriedades visitadas a família trabalhava diretamente na atividade. Dos produtores, $64,4 \%$ faziam parte de algum tipo de associação. As vacas eram divididas em lotes em 28,9\% das propriedades. Apenas $6,7 \%$ dos produtores não forneciam concentrado ao rebanho, enquanto o fornecimento sem critério e o fornecimento por produção era realizado em $22,2 \%$ e $71,1 \%$ das propriedades, respectivamente. A base da alimentação volumosa nas propriedades era pastejo contínuo em $22,2 \%$, pastejo alternado em $13,3 \%$, pastejo rotativo em $51,2 \%$ e fornecimento no cocho em $13,3 \%$. Para reprodução, 59,9\% das propriedades 
utilizava somente monta natural, 6,7\% monta controlada, $15,6 \%$ monta natural e inseminação artificial e $17,8 \%$ somente inseminação artificial. Em relação à ordenha, a mais frequente foi mecânica do tipo balde-ao-pé $(64,4 \%)$, seguida por manual $(20,0 \%)$ e mecânica do tipo canalizada $(15,6 \%)$. Esta pesquisa mostrou a diversidade de produtores e sistemas de produção, além de proporcionar importante experiência ao aluno.

Palavras-chave: Gado leiteiro. Agricultura familiar. Produtividade.

\section{TRANSFORMAÇÃO DE NUTRIENTES DE ORIGEM VEGETAL EM NUTRIENTES DE ORIGEM ANIMAL NA PRODUÇÃO DE FRANGOS DE CORTE}

Transformation of vegetable nutrients in animal source nutrients in broiler production

CELEMI, L. G. A.; MUNHOZ, M. P.; ANJOS, J. R. C.; PINTO, M. F.

Resumo: As linhagens de frango de corte atualmente utilizadas destacam-se por sua eficiente conversão alimentar, que pode ser traduzida como a transformação dos nutrientes ingeridos na ração em massa corpórea, que vai originar produtos de origem animal de alto valor nutricional. Todavia, quando se discute a necessidade do aumento da produção de alimentos para atender à crescente demanda mundial, raramente é considerada a realidade dessa equação de transformação dos nutrientes da ração em massa corporal e, consequentemente, em carne. É necessário se ter sempre em mente que, por mais que a genética, as técnicas de manejo e todos os aspectos relacionados à produção de proteína animal evoluam, a equação será sempre desfavorável. Este trabalho foi delineado para investigar as quantidades de proteína e de energia metabolizável necessárias para produzir frangos de corte, e compará-las com os nutrientes resultantes da carne obtida nesse processo produtivo. Os parâmetros de desempenho esperado para frangos de corte utilizados foram os estabelecidos para a linhagem Cobb 500. Foi considerada uma ave abatida aos 42 dias, pesando $2.732 \mathrm{~g}$, que é o peso estabelecido como média de desempenho para um frango dessa linhagem, com essa idade, em lote misto. Da mesma forma, foram considerados os parâmetros de consumo e as recomendações mínimas para formulação de ração. O rendimento dos cortes e de carne desossada proveniente de cada corte foram calculados. A estimativa do valor nutricional da porção comestível dos cortes de frango utilizou os valores constantes da Tabela Brasileira de Composição de Alimentos (TACO). Os resultados obtidos revelaram que são necessários 902,54 g de proteína e 15.546,98 calorias de energia metabolizável para produzir um frango de 42 dias de idade, com $2.732 \mathrm{~g}$, enquanto a porção comestível obtida a partir desse frango fornece $218 \mathrm{~g}$ de proteína e 2.401 calorias de energia metabolizável. Além dessa relevante redução de nutrientes, essa transformação requer o consumo de água, espaço, oxigênio e energia, gerando diversos produtos indesejáveis, como gases do efeito estufa e dejetos sólidos e líquidos. Portanto, é essencial que se tenha a consciência de que, por mais que a tecnologia envolvida no processo evolua, a produção de carne é um processo ineficiente, tanto em relação à produção de alimentos como em termos de sustentabilidade.

Palavras-chave: Conversão alimentar. Proteína. Frango de corte.

\section{COLOSTOMIA PERMANENTE E PERITONITE CAUSADA POR ESCHERICHIA COLI RESISTENTE À ANTIBIOTICOTERAPIA CONVENCIONAL EM CÃO: RELATO DE CASO}

Permanent colostomy and peritonitis caused by Escherichia coli resistant to conventional antibioticotherapy: case report in a dog

TUBONE, L. T.; ALCÂNTARA, B. M.; SETO, J. A.; ONDAERA, N. N.; PERES, M. L.; EUGÊNIO, F. R.; ANDRADE, A. L.; SANTOS, P. S. P.

Resumo: Foi atendido no hospital veterinário da Faculdade de Medicina Veterinária da Universidade Estadual Paulista (Unesp Araçatuba), um cão, poodle, sete anos, com queixa de disquezia, fezes em "fita" e hematoquezia há um mês. O paciente tinha histórico de ingestão de areia e concreto. Na radiografia abdominal do animal foi observado um aumento de volume em cólon com radiopacidade compatível com tais corpos estranhos. Foi indicada a colotomia para remoção de corpo estranho intestinal, mas durante o procedimento eles não foram observados, havia apenas uma estenose acentuada na porção final do cólon descendente, cuja 
correção foi realizada com incisões longitudinais não perfurantes sobre o estreitamento intramural. Após 13 dias, o animal ainda apresentava tenesmo, por isso, optou-se pela realização de uma colectomia subtotal da porção estenosada. Decorridos quatro dias da colectomia, notou-se conteúdo fecal drenando pelos pontos de pele, evidenciando deiscência da enterorrafia, que foi realizada imediatamente. Entretanto decorridos outros quatro dias, houve nova deiscência dos pontos intestinais o que indicou a realização da técnica de colostomia ventral, nesta ocasião foi colhido material para exames de hemograma, cultura e antibiograma, testando cefepima e enrofloxacino, utilizados como antibioticoterapia anterior. Os resultados de exames complementares diagnosticavam peritonite, com intensa leucocitose e crescimento de Escherichia coli sensível apenas a Imipenem. Foi instituída antibioticoterapia adequada durante 10 dias com o referido antibiótico, havendo melhora do quadro, atestado pelo hemograma. Assim, optou-se pela reversão da colostomia, realizando nova colorrafia com colheita de novo swab peritoneal para cultura e antibiograma. No pós-operatório, foi realizado tratamento com amicacina e metronidazol, já que no primeiro antibiograma havia sensibilidade intermediária à amicacina. Na cultura coletada durante a colorrafia, não houve crescimento bacteriano, comprovando a eficácia do Imipenem. Mesmo com o uso de amicacina e metronidazol, com cinco dias de pós-operatório o animal apresentou-se apático e houve secreção com odor fétido pela ferida cirúrgica, indicando nova ruptura de sutura intestinal. Foi realizada então a colostomia permanente ao flanco esquerdo e instituído pós-operatório com Imipenem. Não houve novas complicações cirúrgicas ou sinais de peritonite após a última cirurgia e o animal manteve-se bem clinicamente durante três meses e meio, quando veio a óbito por motivos não relacionados ao quadro inicial. Tal caso clínico demonstra a importância da realização de exames microbiológicos, como cultura e antibiograma em casos de peritonite e cirurgias intestinais, pois somente com o emprego de tais procedimentos é que foi identificada a causa do insucesso cirúrgico do paciente. Salienta-se, também, que a colostomia pode ser uma alternativa cirúrgica viável em quadros semelhantes, apesar de ser pouco realizada em Medicina Veterinária.

Palavras-chave: Cão. Colostomia. Cultura. Antibiograma. Imipenem.

\section{EXPRESSÃO DE MIRNAS EM LEUCÓCITOS ESPLÊNICOS DE CÃO COM LEISHMANIOSE VISCERAL}

MicroRNA expression in spleen leukocytes from dogs with visceral leishmaniasis

MELO, L. M.; BRAGATO, J. P.; VENTURIN, G. L.; REBECH, G. T.; GARCIA, L. E.; EUGÊNIO, F. R.; SANTOS, P. S. P.; LOPES, F. L.; LIMA, V. M. F.

Resumo: A Leishmania (L.) infantum é o agente etiológico da leishmaniose visceral (LV) no Brasil e representa um grave problema de saúde pública. Investigações realizadas têm demonstrado que a regulação da resposta imune de cães infectados por leishmanias depende de miRNAs. Na VL canina, devido à alta resposta humoral estar associada à progressão da doença, o conhecimento de miRNAs que alteram a resposta imune de humoral para celular pode ser importante na proteção dos cães com LV. Este trabalho foi delineado para identificar os miRNAs diferencialmente expressos em leucócitos esplênicos (LE) de cães naturalmente infectados por $L$. infantum. Foram utilizados cinco cães saudáveis (grupo controle) e 10 cães com VL. O miRNA foi extraído dos LE com o emprego do Mirvana Kit $\left(\right.$ Invitrogen $^{\mathrm{TM}}$ ) de acordo com as recomendações do fabricante, a sua quantificação foi realizada com o fluorômetro (Qubit 3.o, Invitrogen ${ }^{\mathrm{Tu}}$ ), o grau de pureza foi determinado por eletroforese capilar (Bioanalyser, Agilent ${ }^{\mathrm{TM}}$ ) e a armazenagem foi efetuada a $-80^{\circ} \mathrm{C}$. O microarranjo foi realizado com o emprego do kit FlashTag Biotin HSR RNA Labeling (Affymetrix ${ }^{\mathrm{Tu}}$ ), e Affymetrix $^{\text {Tm }}$ miRNA 4.1 Strip, de acordo com as recomendações do fabricante. A produção de cDNA foi executada com o kit miScript RT II (Qiagen ${ }^{\mathrm{TM}}$ ) e a reação do qPCR com iniciadores específicos para miRNAs de cão inventoriados (Qiagen, USA) e SYBR Green (miScript SYBR Green PCR kit, Qiagen ${ }^{\mathrm{Tm}}$ ), seguindo a recomendação do fabricante. A análise foi realizada no Expression Console, Transcriptome Analysis Console (Affymetrix ${ }^{\mathrm{Tm}}$ ) e Anova; o teste de Mann-Whitney foi utilizado para análise dos dados de validação do microarranjo na $\mathrm{QPCR}$; e o IPA (Ingenuity Pathway Analysis) com o teste de Bonferroni para análise de vias canônicas dos Mirna foi utilizado o nível de significância de 0,05. Os miRNAs miR615, miR7 e miR148a apresentaram aumento da expressão, enquanto os miRNAs miR125b e miR125a apresentaram diminuição na expressão no LE de cães com LV. Os miR148a, miR615 e miR21 confirmaram o aumento de sua expressão na 
qPCR. O IPA mostrou 127 vias reguladas por esses miRNAS, cinco vias relacionados com resposta imunológica: STAT3, apoptose desencadeada por células T citotóxicas, sinalização de TGF- $\beta$, via TH2 e sinalização de JAK/Stat, demonstrando a ligação dos miRNA com a regulação da imunidade. A identificação de miRNAs que regula a resposta imune na VL canina pode criar estratégias imunoterapêuticas que devem ser mais investigadas.

Palavras-chave: Leucócitos. MiRNA. Microarranjo. Leishmaniose.

\section{PROBLEMAS REPRODUTIVOS DE ÉGUAS MANTIDAS EM PEQUENAS PROPRIEDADES NA REGIĨO DE ARAÇATUBA/SP, BRASIL}

Reproductive problems of mares kept on small properties in the Araçatuba region - São Paulo state, Brazil

SANTANA, L. R.; BOMFIM, C. A. M.

Resumo: Os problemas reprodutivos dos equídeos, principalmente de éguas, vêm acarretando perdas na equideocultura. Os fenômenos fisiológicos da reprodução equina requerem muita atenção para que a eficiência reprodutiva seja bem-sucedida. Pensando nisto e no pouco conhecimento que se tem sobre a amplitude da estação reprodutiva dos animais criados na região de Araçatuba, estado de São Paulo, Brasil, esta pesquisa foi realizada para investigar o manejo reprodutivo e os principais problemas reprodutivos observados em éguas mantidas em uma amostra, estabelecida por conveniência, de pequenas propriedades localizadas na referida região. O comportamento reprodutivo sazonal fisiológico - fotoperíodo positivo, predisposições a alterações anatômicas pós-parto, e as enfermidades do aparelho reprodutor demandam dos criadores conhecimentos técnicos para implementação do manejo reprodutivo mais adequado. Dentre as enfermidades reprodutivas dos equinos, a endometrite é considerada a principal causa de infertilidade em éguas. Contudo, as alterações anatômicas do aparelho reprodutor, a contaminação por micro-organismos, as alterações fisiológicas próprias da idade e outras predisposições individuais que são de difícil diagnóstico, também podem estar envolvidas. A lesão de períneo, esfíncter anal, e de comissura vulvar e dorsal são problemas reprodutivos facilmente perceptíveis em uma inspeção visual. Este trabalho utilizou 57 éguas, registradas em ficha de cadastro e avaliadas por exame ginecológico. Quando necessário, também foi realizada a citologia uterina, a ultrassonografia ou outros exames laboratoriais. A pesquisa foi realizada entre os anos de 2013 e 2016 e para todas as éguas participantes havia termo de consentimento do proprietário. Os problemas reprodutivos mais frequentes foram: subfertilidade que não pode ser diagnosticada por exame ginecológico e exames complementares $(36,4 \%)$ e a laceração de períneo de Grau I (24,2\%). O manejo reprodutivo adotado nas pequenas propriedades consistia na utilização apenas de cobertura natural das éguas $(61,4 \%)$, inseminação artificial $(21,1 \%)$ ou utilização das duas técnicas (17,5\%). Os proprietários que utilizavam apenas cobertura natural eram de baixa renda e não tinham nenhuma orientação técnica, portanto, poderiam estar adotando procedimentos inadequados. Todas as éguas com subfertilidade não diagnosticada e que foram submetidas à técnica de Inseminação Artificial, se tornaram prenhes. A conclusão obtida foi que a maioria dos casos de problemas reprodutivos observados em éguas mantidas em pequenas propriedades na região de Araçatuba/SP provavelmente decorrem do manejo reprodutivo inapropriado devido à falta de orientação técnica, contudo não pode ser excluída a ocorrência de alguma disfunção reprodutiva decorrente de distúrbio endócrino relacionado aos hormônios ligados à reprodução.

Palavias-chave: Subfertilidade. Prenhez. Endometrite. Equino.

\section{DISTOCIA EM PERIQUITO AUSTRALIANO (MELOPSITTACUS UNDULATUS) ASSOCIADA A DEFICIÊNCIAS NO MANEJO ALIMENTAR}

Dystocia in budgerigar (Melopsittacus undulatus) associated with food management deficiencies

JESUS, L. P.

Resumo: Casos de distocia são frequentes em aves de cativeiro e estão muitas vezes relacionados com erros de manejo. Dietas desbalanceadas podem ser associadas à retenção de ovos. Este trabalho relata o caso de um periquito australiano (Melopsittacus undulatus), fêmea adulta, com retenção de ovo que foi tratado no Hospital Veterinário Luiz Quintiliano de Oliveira, da Faculdade de Medicina Veterinária da Universidade Estadual Paulista (FMV-Unesp Araçatuba), no setor de clínica de animais silvestres. A queixa principal do proprietário foi a apatia do animal. $\mathrm{Na}$ anamnese foi relatado período de ovopostura e uma dieta baseada em mistura de sementes. No exame clínico foram observados sinais clínicos caracterizados 
por dispneia, apatia e penas eriçadas. Pela palpação, havia aumento de volume na parte caudal de cavidade celomática, que foi visualizado, pelo exame radiográfico, como uma estrutura radiopaca de formato ovalado. O tratamento realizado foi efetuado com glutamato de cálcio $(7 \mathrm{mg} / \mathrm{kg})$ e três aplicações de ocitocina ( $0,5 \mathrm{UI} / \mathrm{kg}$ ) a cada uma hora, acompanhado de aquecimento, oxigenação e fluidoterapia subcutânea aquecida $(20 \mathrm{mg} / \mathrm{kg})$. O tratamento durou quatro horas sem que o animal conseguisse expulsar o ovo. O animal foi enviado para casa do proprietário com a recomendação de aquecimento e repouso. No dia seguinte, o proprietário retornou com a ave clinicamente estável, relatando ovopostura na madrugada, juntamente com o ovo, o qual apresentava deformidades em seu formato, o que contribuiu para que ficasse retido. A alimentação de psitaciformes em vida livre é baseada em sementes, castanhas, coquinhos, frutas e outros vegetais, diferentemente dos animais de cativeiro, para os quais são indicadas as rações extrusadas (CUBAS, 2014). Uma dieta baseada somente em mistura de sementes, como no caso relatado, é carente em cálcio, nutriente essencial para a formação da casca dos ovos (PÉRON, 2014). A deficiência de cálcio pode ocasionar problemas na formação da casca, diminuição nas contrações para ovipostura e distocia (BENES, 2004). Sendo o erro de manejo alimentar uma das principais causas dos problemas de retenção e formação de ovos, a dieta de aves não deve se basear somente em mistura de sementes, devido ao seu alto teor de gorduras vegetais e carência de nutrientes como o cálcio. A alimentação adequada de aves ornamentais deve ser constituída por rações extrusadas específicas para a espécie, juntamente com frutas, verduras e legumes, que proporcionam um melhor balanço nutricional.

Palavras-chave: Psitacídeos. Cálcio. Retenção. Ovo.

\section{ANOFTALMIA BILATERAL EM PORQUINHO DA ÍNDIA: RELATO DE CASO}

Bilateral anophthalmia in a guine pig: case report

\author{
ALBUQUERQUE, L. I. L.; PINOTI, L. D. R.; BRUNO, \\ D. B.; GARCIA, S. D.
}

Resumo: Anoftalmia, ou ausência completa de bulbo ocular, é uma afecção rara em cães e gatos e ainda sem descrição em pets exóticos, como em porquinhos da índia (Cavia porcellus). Nesse caso, não há evidências de estruturas oculares tanto nos exames clínicos quanto ultrassonográficos. A anoftalmia ocorre devido a um crescimento inadequado da cúpula ou vesícula óptica, ainda em estágio precoce da gestação, ou mesmo por falha da expansão desse elemento óptico Anormalidades oculares congênitas múltiplas de origem hereditária podem ser observadas em todas as espécies e, por esse motivo, estes animais devem ser retirados da reprodução. Para confirmação da ausência de conteúdo ocular intraorbitário ou presença de conteúdo remanescente do sistema ocular, realiza-se o exame histopatológico e, para isso, é necessário que o paciente tenha a abertura completa da fissura palpebral para a colheita do material. Tal técnica é considerada de caráter invasivo, porém há outras formas de diagnóstico, entre elas, o exame clínico oftalmológico e a avaliação por meio de técnicas de imagem, como ultrassonografia ocular. A ultrassonografia proporciona avaliação de pequenas estruturas com grande qualidade de imagem e de modo não invasivo. Foi atendido pelo Setor de Clínica de Animais Silvestres, do Hospital Veterinário Luiz Quintiliano de Oliveira, da Faculdade de Medicina Veterinária da Universidade Estadual Paulista (Unesp Araçatuba), um porquinho da índia, com cinco dias de idade, histórico de não abrir os olhos e sem dificuldade na alimentação. Ele havia nascido com peso corpóreo parecido ao outro filhote da ninhada e sem anormalidades clínicas. Durante o exame físico foi constatado que as pálpebras estavam fechadas e por palpação percebia-se que havia duas estruturas arredondadas, sem a presença de bulbos oculares aparentes. Todos os parâmetros vitais avaliados estavam dentro dos limites de normalidade. Foi realizado o exame ultrassonográfico com sonda microlinear de $21 \mathrm{Mhz}$ e não foi observada a presença de conteúdo intraorbitário em nenhum olho. Este é o primeiro relato de anoftalmia em porquinho da índia no Brasil, tendo a confirmação diagnóstica com o emprego de ultrassonografia ocular.

Palavras-chave: Anoftalmia. Porquinho da índia. Cavia porcellus.

33. HIPOPLASIA EPIFISEAL UMERAL, RADIAL E ULNAR UNILATERAL EM CÃO: RELATO DE CASO

Unilateral humeral, radial and ulnar epiphysial hypoplasia in dog: case report

ALBUQUERQUE, L. I. L.; PINOTI, L. D. R.; ALCÂNTARA, B. M.; EUGÊNIO, F. R.

Resumo: Anomalias ósseas congênitas podem afetar cães e gatos de diversas raças. Algumas destas 
deformidades ocorrem isoladamente, entretanto, podem estar associadas a síndromes sistêmicas e gerar deformidades em diversos órgãos, sendo necessária uma avaliação geral deste paciente. Estas anomalias são geralmente detectadas ao nascimento e são em sua maioria resultado de fatores in útero, podendo ser também de caráter hereditário. A hipoplasia epifiseal consiste em uma redução ou atraso de ossificação, uni ou bilateral, do modelo de cartilagem epifiseal. A região mais acometida é a epífise proximal de tíbia e em côndilos umeral e femoral. O exame radiográfico é o procedimento tido como de eleição para avaliação e diagnóstico de tais casos. Um cão da raça bulldog francês, com dois meses de idade, histórico de claudicação e dor na palpação em articulação umeroradioulnar de membro torácico esquerdo. Foi atendido pelo setor de clínica cirúrgica de pequenos animais do Hospital Veterinário Luiz Quintiliano de Oliveira, da Faculdade de Medicina Veterinária da Universidade Estadual Paulista (FMV-Unesp Araçatuba). O paciente foi encaminhado ao setor de diagnóstico por imagem para realização de exame radiográfico, com suspeita de displasia do cotovelo ou fratura Salter-Harris. Ao exame, foi visibilizado um retardo de ossificação em epífise proximal de rádio, em processo ancôneo de ulna e em côndilos umerais, quando comparado ao membro contralateral. O paciente foi submetido à imobilização do membro com utilização de tala externa, após suspeita inicial de fratura em epífises, mas após análise adequada foi sugerida a retirada da tala e o acompanhamento radiográfico periódico para observação do desenvolvimento ósseo. Após três retornos, exames radiográficos e com histórico de ausência de claudicação, confirmou-se que as alterações radiográficas iniciais consistiam em maior ossificação epifiseal, mesmo que retardada em relação ao membro contralateral. O conhecimento do período de fechamento epifisário é fundamental para que não ocorram diagnósticos equivocados e sejam instituídos tratamentos inadequados. Este relato é um alerta para a importância do trabalho em equipe e do diagnóstico de alterações epifiseais, evitando o fechamento fisário prematuro e consequentemente assimetria de desenvolvimento ósseo da articulação em estudo.

Palavras-chave: Hipoplasia epifiseal. Anomalias congênitas. Displasia do cotovelo.

\section{A INFUSÃO CONTÍNUA DE REMIFENTANIL NÃO ALTERA A FUNÇÃO SISTÓLICA E DIASTÓLICA VENTRICULAR ESQUERDA EM CÃES ANESTESIADOS COM PROPOFOL}

Continuous infusion of remifentanil does not impair left ventricular systolic and diastolic function, in dogs anesthetized with propofol

MARQUES, M. G.

Resumo: Este trabalho avaliou os efeitos da infusão contínua de remifentanil na função sistólica e diastólica do ventrículo esquerdo de cães anestesiados com propofol. Foram utilizados seis cães da raça beagle: dois machos e quatro fêmeas, não castrados, com idade de cinco anos, com peso médio de $13,0 \pm 2,5 \mathrm{~kg}$. Os cães foram submetidos a dois tratamentos experimentais com intervalo mínimo de sete dias. No primeiro tratamento foi realizada a infusão contínua de propofol (GP) na taxa de $0,6 \mathrm{mg} / \mathrm{kg} /$ minuto, já no segundo foi utilizada a infusão contínua de propofol e remifentanil (GPR) nas taxas de $0,6 \mathrm{mg} / \mathrm{kg} /$ minuto e $0,3 \mu \mathrm{g} / \mathrm{kg} /$ minuto, respectivamente. As principais variáveis analisadas foram: frequência cardíaca (FC), pressão arterial média (PAM), índice de resistência vascular periférica (IRVP), índice cardíaco Doppler (ICD), fração de encurtamento (FEC), fração de ejeção (FEJ), onda S', relação E/A e relação E'/A'. As avaliações foram efetuadas antes da administração dos fármacos $(\mathrm{MB})$ e decorridos 20, 40 e 60 minutos (M2o, M40 e M6o) da administração. Houve redução semelhante dos índices de função sistólica (FEC, FEJ e onda S') e da PAM em ambos os tratamentos. Entretanto, os valores permaneceram dentro da normalidade para cães anestesiados. Nos animais tratados com remifentanil houve diminuição significativa da FC e ICD. No TPR, a relação E/A permaneceu acima 1,80 , todavia, a avaliação Doppler tecidual pulsado (relação E'/A') mostrou padrão de relaxamento normal. A conclusão obtida foi que o emprego do remifentanil na taxa de $0,3 \mu \mathrm{g} / \mathrm{kg} / \mathrm{min}$ não alterou a função sistólica e diastólica do ventrículo esquerdo em cães hígidos anestesiados com propofol, mostrando-se seguro, sob o ponto de vista cardiovascular.

Palavras-chave: Diástole. Ecocardiografia. Miocárdio. Opioide. Sístole. 
35. ZOONOSES DIAGNOSTICADAS NO SERVIÇO DE PATOLOGIA ANIMAL DA FACULDADE DE MEDICINA VETERINÁRIA DE ARAÇATUBA NO PERÍODO DE JANEIRO A AGOSTO DE 2017

Zoonoses diagnosed in the service of animal pathology of Faculdade de Medicina Veterinária de Araçatuba in the period of January to August-2017

TOSCANO, M. F.; OLIVEIRA, F. C.; MIRANDA, M. F. S.; ROZZA, D. B.; MACHADO, G. F.; LUVIZOTTO, M. C. R.

Resumo: A deteç̧ão e notificação de agentes patogênicos são pontos fundamentais para prevenção e controle de enfermidades tanto no âmbito nacional como no global. Além disso, inúmeras afecções são classificadas como zoonoses. Diversos autores apontam um aumento gradual dos casos de patologias zoonóticas nos últimos anos devido às constantes modificações causadas pelo homem no ambiente. A Organização Mundial da Saúde refere que a leptospirose e leishmaniose estão na lista das principais doenças transmitidas dos animais para os humanos no Brasil. Este trabalho é um estudo das principais zoonoses diagnosticadas pelo serviço de Patologia Animal da Faculdade de Medicina Veterinária da Universidade Estadual Paulista (FMVUnesp Araçatuba), na rotina de exames necroscópicos e histopatológicos, no período de janeiro a agosto de 2017. As zoonoses diagnosticadas, de acordo com o número de casos e espécies acometidas foram: leishmaniose (50 cães), leptospirose (dois cães), raiva (um equino), criptosporidiose (um bovino), pitiose (quatro equinos) e linfadenite caseosa (um ovino). Os diagnósticos referidos foram concluídos a partir das análises dos históricos dos animais, sinais clínicos, alterações macroscópicas e microscópicas e exames complementares (por exemplo: colorações especiais). O elevado número de cães diagnosticados com leishmaniose visceral está relacionado ao fato da região de Araçatuba/SP ser considerada endêmica para a doença; e o diagnóstico conclusivo foi firmado pela visualização de formas amastigotas de Leishmania sp. em exames citológicos de diversos órgãos (como linfonodo, fígado, baço e medula óssea). Os diagnósticos de leptospirose e raiva foram concluídos por meio da associação entre lesões macroscópicas e microscópicas, avaliadas pelo serviço de patologia, e testes específicos realizados pelo laboratório de microbiologia da FMVUnesp Araçatuba. O diagnóstico de linfadenite caseosa foi determinado a partir da observação de linfadenite piogranulomatosa em um ovino, lesão que é associada à infecção por Corynebacterium pseudotuberculosis. Para o diagnóstico de criptosporidiose e pitiose foram utilizadas colorações especiais para detecção dos agentes infecciosos no material encaminhado. A conclusão obtida foi que os exames macroscópicos, histopatológicos e microbiológicos realizados foram essenciais para o estabelecimento do diagnóstico conclusivo, confirmando a ocorrência de zoonoses na cidade/ região de Araçatuba/SP, Brasil, que devem ser objeto de medidas específicas de controle.

Pallavras-chave: Zoonoses. Diagnóstico. Patologia. Saúde Única.

\section{ANESTESIA MULTIMODAL COM BLOQUEIO PARAVERTEBRAL CERVICAL MODIFICADO PARA OSTEOSSÍNTESE DE FRATURA COMPLETA OBLÍQUA DE ÚMERO EM POTRO: RELATO DE CASO}

Multimodal anesthesia with paravertebral cervical block for osteosynthesis of complete oblique humeral fracture in foal: a case report

ENEAS, M. D.

Resumo: Um equino de cinco meses de idade, macho, $180 \mathrm{~kg}$ de peso vivo, quarto-de-milha foi atendido no hospital veterinário da Faculdade de Medicina Veterinária da Universidade Estadual Paulista (Unesp Araçatuba), em maio de 2017 apresentando trauma no membro torácico esquerdo. $\mathrm{Na}$ chegada ao hospital veterinário, o animal não apoiava o membro traumatizado e apresentava dor. No exame radiográfico foi diagnosticado fratura completa oblíqua de úmero, optando-se então pelo tratamento cirúrgico. Devido à localização da fratura em úmero, a técnica escolhida foi o bloqueio paravertebral cervical, procedimento não muito empregado em equinos, pelo impossibilidade de localização das estruturas anatômicas por palpação em animais adultos. A medicação pré-anestésica utilizada foi xilazina $2 \%(0,5 \mathrm{mg} / \mathrm{kg} /$ IV) e como indução anestésica cetamina 10\% (2 mg/ $\mathrm{kg})$ e midazolam $0,5 \%(0,5 \mathrm{mg} / \mathrm{kg})$, ambos administrados pela via intravenosa, seguido da manutenção anestésica com isofluorano. O bloqueio paravertebral 
cervical foi realizado com ropivacaína 0,75\% em três pontos distintos e com o auxílio de estimulador de nervos periféricos (Stimuplex HNS 12), que possibilita maior precisão nos bloqueios perineurais e permite a administração de menor volume de anestésico local. Foram aplicados $6 \mathrm{~mL}(0,25 \mathrm{mg} / \mathrm{kg})$ de anestésico local nos espaços dorsocranial e dorsocaudal do processo transverso de C6 e na convergência dos ramos ventrais de $\mathrm{C} 8$ e $\mathrm{T} 1$ na margem cranial da primeira costela. A localização destes nervos foi iniciada com uma corrente estimuladora de $1 \mathrm{~mA}(2 \mathrm{~Hz}, 0,1 \mathrm{~ms}$ ), quando desencadeada resposta positiva; a corrente foi reduzida e a agulha reposicionada até que a resposta positiva fosse obtida por uma corrente de $0,3 \mathrm{~mA}$ e negativa na corrente de $0,2 \mathrm{~mA}$, evitando aplicação intraneural do anestésico local. Durante o procedimento cirúrgico foram monitorados: frequência cardíaca (FC), frequência respiratória $(f)$, saturação de oxihemoglobina $\left(\mathrm{SpO}_{2}\right)$, dióxido de carbono ao final da expiração $\left(\mathrm{ETCO}_{2}\right)$, pressão arterial sistólica, diastólica e média (PAS, PAD e PAM), temperatura (T) e concentração anestésica expirada (Etiso V\%). Os parâmetros avaliados mantiveram-se dentro dos valores de referência, indicando eficácia do bloqueio, não sendo necessária infusão de nenhum analgésico. Houve apenas redução gradual da temperatura ao longo do procedimento. No pós-operatório imediato foi administrado morfina $1 \%(0,1 \mathrm{mg} / \mathrm{kg})$ por via epidural e fenilbutazona $(4,4 \mathrm{mg} / \mathrm{kg} / \mathrm{IV})$ como terapia analgésica. $\mathrm{O}$ animal foi extubado em cinco minutos e manteve-se em posição quadrupedal 40 minutos após a extubação. O protocolo anestésico, associado ao bloqueio regional, foi eficiente e seguro para a realização de procedimentos cirúrgicos em equinos jovens.

Palavra-chave: Osteossíntese. Anestesia local. Potros.

\section{HIPOPLASIA MEDULAR POR USO DE CIPIONATO DE ESTRADIOL EM CADELA: RELATO DE CASO}

Case report about medullary hypoplasia following the use of estradiol cypionate in bitches

FARIA, M. C.; ALVES, I. P.; FERRARINI, J. C. M.; ALVES, B. M. S. M.; RAMOS, P. H. O.; KOIVISTO, M. B.

Resumo: O estrógeno e seus derivados são amplamente utilizados na rotina veterinária como método contraceptivo e abortivo. Vários efeitos adversos podem ocorrer, dentre eles é citada a hipoplasia/ aplasia medular. Uma cadela, SRD, com quatro anos de idade, pesando $8,2 \mathrm{~kg}$, foi atendida no hospital veterinário da Faculdade de Medicina Veterinária da Universidade Estadual Paulista (FMV-Unesp Araçatuba), apresentando hiporexia há três dias, edema vulvar e secreção vaginal sanguinolenta. $\mathrm{O}$ tutor relatou que havia efetuado duas aplicações de cipionato de estradiol com intervalo de três meses, após ter observado que o animal havia copulado com um cão de rua. Ao exame físico todos os parâmetros estavam dentro da normalidade. Foi realizada coleta de sangue e exame ultrassonográfico para avaliação uterina. O exame revelou corpo do útero e cornos uterinos ecogênicos, parede espessada, sem conteúdo intralumial, e presença de lesões císticas em cornos. Os diâmetros do corpo do útero e dos cornos uterinos foram de $0,58 \mathrm{~cm}$ e $1,10 \mathrm{~cm}$, respectivamente, sugestivos de hiperplasia endometrial cística. No hemograma foi constatado presença de valores baixos para todas as linhagens celulares, especialmente para os leucócitos e plaquetas. Dez dias após o primeiro atendimento o animal retornou ao hospital veterinário com aumento do sangramento vaginal e pseudociese. Em uma nova colheita de sangue para hemograma e perfil bioquímico foi observado pancitopenia severa e aumento dos valores da Fosfatase alcalina (FA) $(226 \mathrm{U} / \mathrm{L})$ e ureia $(10,8 \mathrm{mmol} / \mathrm{L})$. Foi realizada transfusão sanguínea seguida de ovariohisterectomia para retirada da causa base do sangramento vaginal advindo do útero, pois o mielograma confirmou hipoplasia medular. $\mathrm{O}$ animal está se recuperando bem e continuará em acompanhamento. $\mathrm{O}$ uso frequente de estrógenos sintéticos em cadelas como método contraceptivo ou para interrupção de gestação pode acarretar mielotoxicidade acompanhada, muitas vezes, pelo complexo hiperplasia endometrial cística/ piometra e até levar o animal a óbito. Neste caso os sinais clínicos apresentados foram condizentes com os relatados na literatura, indicando pancitopenia e hemorragias. É necessário evitar o uso indiscriminado desse tipo de terapia hormonal devido às alterações clínicas adversas que podem ocorrer.

Palavras-chave: Mielotoxicidade. Cadelas. Estrógeno. 


\section{URETEROTOMIA PARA REMOÇÃO DE CÁLCULO URETERAL EM CANÍDEO: RELATO DE CASO}

Reterotomy for removal of ureteral in a dog: a case report

PERES, M. L.

Resumo: Foi atendida a cadela schnauzer Mini, de nove meses de idade pelo serviço de clínica cirúrgica no hospital veterinário, em setembro de 2017 com histórico de litíase ureteral, previamente diagnosticada por profissional, pela ultrassonografia. Foi relatado que o paciente estava hiporético, apático, com êmese e, ao exame de palpação, apresentava dor abdominal. Foram solicitadas radiografia e ultrassonografia abdominais, além de hemograma, exames bioquímicos, hemogasometria e urinálise. No primeiro exame ultrassonográfico foram observadas alterações sugestivas de nefrite intersticial crônica e hidronefrose moderada. O ureter esquerdo encontrava-se dilatado com presença de estrutura hiperecogênica formadora de sombra acústica, medindo aproximadamente $0,42 \mathrm{~cm}$, localizada em porção caudal, sugestivo de litíase. O ureter direito estava dilatado, com presença de estrutura hiperecogênica formadora de sombra acústica, localizado em porção cau$\mathrm{dal}$, medindo aproximadamente $0,33 \mathrm{~cm}$. Diante do caso, prescreveu-se enrofloxacino, ranitidina, escopolamina, cloridrato de tramadol e tansulosina, agendando-se cirurgia para ureterotomia. Após três semanas, repetiu-se o exame ultrassonográfico, no qual os rins apresentavam-se com alterações sugestivas de glomerulonefrite e displasia em rim direito; hidronefrose e hidroureter moderado por presença de litíase em rim e ureter esquerdos, além de hidronefrose discreta em rim direito. Neste exame o cálculo ureteral direito não estava mais presente e, por esse motivo, optou-se por ureterotomia esquerda, sendo o procedimento realizado dois dias após o exame. A abordagem no ureter esquerdo foi realizada por incisão longitudinal sobre o cálculo, seguida de sua remoção e síntese da parede com sutura transversa e fio vicryl 6-o. Foi colocada uma sonda nasogástrica quatro como cateter duplo "J" no interior do ureter indo até próximo à pelve, seguindo caudalmente até a vesícula urinária e uretra, sendo fixado na parte externa da vulva. O cálculo ureteral foi encaminhado para análise mineral e o cateter foi mantido por 48 horas, sendo que nos dois primeiros retornos (dois e sete dias de pós-operatório), o animal se encontrava em excelente estado clínico, sem vômito e com apetite. O cálculo analisado era composto por oxalato de cálcio. A raça do animal deste relato tem a predisposição congênita para ocorrência da displasia renal e metabólica para a formação de urólitos, além de outros fatores complicantes secundários, como infecção bacteriana (cistite/pielonefrite). Este relato reforça a importância do diagnóstico precoce de litíase ureteral, uma vez que cirurgia de ureterotomia para remoção da obstrução é totalmente possível e exitosa. A aplicação do cateter intraureteral, mimetizando o cateter duplo "J", foi útil para a segurança da sutura.

Palavras-chave: Ureterotomia. Cão. Urólito. Ureter. Hidronefrose.

\section{HIPERPARATIREOIDISMO SECUNDÁRIO RENAL EM UM CÃO COM DOENÇA RENAL CRÔNICA: RELATO DE CASO}

Renal secondary hyperpraratioidism in a dog with chronic renal disease: case report

RIBEIRO, M. L. S.; GAMES, B. M. M.; SOUZA, F. G. S.; ALBUQUERQUE, L. I. L.; FERREIRA, W. L.

Resumo: O hiperparatireoidismo é uma complicação decorrente da doença renal crônica (DRC) em estágio avançado. A perda progressiva das funções glomerular e tubular resultam em hiperfosfatemia, hipocalcemia e aumento da secreção de paratormônio (PTH) pelas glândulas paratireoides. Este hormônio aumenta a atividade osteoclástica, levando à absorção de cálcio e fósforo dos ossos e maior reabsorção de cálcio pelos rins, ocasionando osteopenia e mineralização de tecidos moles. A desmineralização óssea ocorre com a progressão da DRC à medida que a atividade osteoclástica aumenta para manter a homeostasia do cálcio. Os ossos mais vulneráveis à desmineralização são os ossos alveolares dentários e o osso esponjoso da maxila e da mandíbula. Radiografias do crânio podem evidenciar osteopenia e mineralização de tecidos moles. Mandíbula flexível macia ou "mandíbula de borracha", fraturas patológicas e dor óssea são sinais sugestivos de osteodistrofia fibrosa secundária a insuficiência renal. A mensuração da concentração de cálcio ionizado pode ajudar no estabelecimento da distinção entre hiperparatireoidismo primário e hiperparatireoidismo secundário renal, onde o cálcio ionizado é aumentado ou normal, ou diminuído, respectivamente. As concentrações séricas de cálcio total podem estar normais, aumentadas ou diminuídas, fósforo aumentado, calcitriol normal ou diminuído, e PTH aumentado. Um canino, macho, da raça lhasa apso, 
seis anos de idade, foi atendido com histórico de poliúria, polidipsia, emagrecimento progressivo, hiporexia e apatia há duas semanas. Ao exame físico foi constatado desidratação intensa, hálito urêmico, mucosas hipocoradas, mobilidade anormal em região de mandíbula e maxila, com aspecto maleável e consistência macia. Os exames hematológicos indicaram anemia, azotemia severa, hipoalbuminemia, e hiperfosfatemia. Na urinálise foi observada densidade urinária baixa e proteinúria. Na hemogasometria a concentração de cálcio ionizado estava diminuída. No exame ultrassonográfico foi visibilizado rins com contornos irregulares, ecogenicidade severamente aumentada, relação córtico-medular severamente diminuída, com dimensões mantidas em rim esquerdo e diminuídas em rim direito, e sugestivo de DRC com possibilidade de displasia em rim direito. As radiografias de crânio evidenciaram desmineralização generalizada dos ossos do crânio, com severa diminuição de radiopacidade da mandíbula e maxila com aparência sugestiva de perda da sustentação óssea dos dentes. O animal foi diagnosticado com DRC em estágio quatro, com desenvolvimento de osteodistrofia fibrosa por hiperparatireoidismo secundário renal. Apesar do tratamento clínico intensivo ter sido instituído, o cão veio a óbito em decorrência do agravamento do quadro urêmico e das consequências da osteodistrofia fibrosa. A DRC avançada com osteodistrofia fibrosa respondem insatisfatoriamente ao tratamento, ressaltando a importância do diagnóstico precoce, devido sua alta prevalência na clínica de pequenos animais.

Palavras-chave: Rins. Doença renal crônica. Cão. Paratireoides. Osteodistrofia fibrosa.

\section{PERFORMANCE DAS TÉCNICAS PARA MINIMIZAR O ESTRESSE TÉRMICO AGUDO OU CRÔNICO EM FRANGOS DE CORTE}

Performance of techniques to minimize of acute heat stress or chronic in broilers

RODRIGUES, M. M.; SANDRE, D. G.; GARCIA NETO, M.; PERRI, S. H. V.

Resumo: O equilíbrio eletrolítico na dieta e o condicionamento térmico precoce são técnicas utilizadas na avicultura para minimizar o estresse calórico. Este trabalho foi delineado para avaliar possíveis interações e efeitos do equilíbrio eletrolítico na dieta e do condicionamento térmico precoce sobre o consumo de ração $(\mathrm{kg})$, peso vivo $(\mathrm{kg})$, conversão alimentar, mortalidade (\%), índice bioeconômico energético (Mcal/ $\mathrm{kg}$ ), umidade de excretas (\%), gordura cavitária (g) e coloração de peito $\left(\mathrm{L}^{\star} \mathrm{a}^{\star} \mathrm{b}^{\star}\right)$ em frangos de corte em condições de estresse térmico agudo ou crônico. Foram utilizados 1.280 pintos, divididos em: experimento I (estresse crônico, período: $35^{\circ}$ ao $39^{\circ}$ dia, $6 \mathrm{~h} /$ dia a $32^{\circ} \mathrm{C}$ ) e experimento II (estresse agudo, período: $38^{\circ}$ dia, $6 \mathrm{~h}$ a $36^{\circ} \mathrm{C}$ ), combinados num arranjo fatorial $2 \times 2 \times 2$, com e sem condicionamento térmico precoce (CTP); dieta com e sem equilíbrio eletrolítico (EE) e estresse térmico agudo ou crônico. Para aplicação do CTP, metade das aves foram expostas a $36^{\circ} \mathrm{C}$ durante 24 horas com a idade de cinco dias. Não houve interação entre nenhum dos parâmetros avaliados. Houve aumento expressivo da mortalidade nas aves expostas ao estresse agudo. $\mathrm{O}$ EE aumentou a umidade nas excretas. Aves submetidas a estresse crônico apresentaram menores conteúdos de lipídios nos tecidos. Além disso, para os valores $\mathrm{L}^{*} \mathrm{e}$ $\mathrm{b}^{*}$, houve um aumento no estresse agudo em relação ao crônico.

Palavras-chave: Aves. Balanço eletrolítico. Nutrição animal. Síndrome músculo pálido.

\section{MIROMA HIPOCAMPAL DE RATOS INFANTES COM MENINGITE PNEUMOCÓCICA TRATADOS COM VITAMINA B12 OU PLACEBO}

Hippocampal mirome of infant rats with pneumococcal meningitis treated with vitamin $\mathrm{B} 12$ or placebo

SCARAMELE, N. F.; QUEIROZ, K. B.; MATOS, D. J.; GARCIA, L. E.; MARINHO, M.; COIMBRA, R. S.; LOPES, F. L.

Resumo: As meningites bacterianas agudas ocorrem quando bactérias alcançam o sistema nervoso central, desencadeando uma resposta imunológica inata exacerbada que culmina em lesões necróticas no córtex e apoptose das células progenitoras e neurônios pós-mitóticos do giro denteado do hipocampo. Já foi demonstrado que a terapia adjuvante com vitamina B12 é anti-inflamatória e neuroprotetora para o hipocampo (COIMBRA et al., 2014). Os microRNAs (miRNAs) são pequenos RNAs não-codantes associados ao controle pós-transcricional de seus genes-alvo. Este trabalho foi delineado para elucidar os padrões de expressão global dos miRNAs (miRoma) durante a meningite pneumocócica, e em 
resposta à terapia com $\mathrm{B} 12$. Dezesseis ratos Wistar com 11 dias de idade foram infectados, por injeção intracisternal, com Streptococcus pneumoniae do sorotipo 3, ou salina (SHAM), e tratados com vitamina B12 $(6,25 \mathrm{mg} /$ $\mathrm{Kg}$ ), ou salina (placebo), por via intramuscular, às $3 \mathrm{~h} \mathrm{e}$ $18 \mathrm{~h}$ após a infecção (p.i.). Todos os animais receberam ceftriaxona $(100 \mathrm{mg} / \mathrm{Kg})$ às $18 \mathrm{~h}$ p.i. Os animais foram eutanasiados 24 h p.i. e seus hipocampos removidos para extração de RNA total. Analisando a influência da infecção (INF vs. SHAM), foi observado que 22 miRNAs estavam positivamente regulados e sete negativamente ( $P<$ o,o1, Fold-Change $\geq 1,5$ ), enquanto o efeito do tratamento adjuvante de $\mathrm{B} 12$ em indivíduos infectados $(\mathrm{INF}+\mathrm{B} 12$ vs. INF + placebo) regula dois miRNAs positivamente e seis negativamente. Ao comparar indivíduos não-infectados tratados com B12 com indivíduos saudáveis e tratados com B12 (SHAM + B12 vs. SHAM + placebo) houve regulação positiva de dois e regulação negativa de 1 miRNA. As análises efetuadas com o programa Ingenuity Pathway Analysis mostraram que, dos 37 miRNAs regulados, 11 são responsáveis por regular a expressão de 240 genes-alvo experimentalmente observados. Estes genes-alvo estão envolvidos em diversas vias relacionadas a processos imunológicos e de regulação de apoptose, como sinalização de IL-6, IL-8, IL-10, PPAR, NF- $\kappa B$, Toll-like receptor, dentre outros. A princípio, pode-se inferir que a infecção regula, de forma ativa, miRNAs envolvidos em processos inflamatórios e de regulação da apoptose, que o tratamento adjuvante com B12 atenua a alteração dos miRNAs induzida pela infecção, e que o uso de B12 em indivíduos saudáveis não altera de forma significativa o miRoma hipocampal.

Palavras-chave: Meningite. Streptococcus pneumoniae. MicroRNAs. Vitamina B12. Epigenética.

\section{PIOMETRA E VIABILIDADE FETAL EM CADELA: RELATO DE CASO}

Pyometra and fetal viability in a bitch: case report

OLIVEIRA, P. R. H.; ALVES, I. P.; SILVA, F. E.; ALVES, B. M. S. M.; FARIA, M. C.; FERRARINI, J. C.; PINOTI, L. D. R.; KOIVISTO, M. B.

Resumo: O complexo hiperplasia endometrial cística-piometra acomete fêmeas adultas inteiras, sendo desencadeado por repetidas exposições do endométrio à progesterona, criando um ambiente prolífero a bactérias oportunistas e produção de exudato inflamatório. A presença simultânea desta afecção e gestação gerando filhotes viáveis é pouco descrita na literatura. Uma fêmea canina gestante, SRD, 13 anos de idade, foi levada ao hospital veterinário da Faculdade de Medicina Veterinária da Universidade Estadual Paulista (FMV-Unesp Araçatuba), devido à observação de secreção vulvar transparente. $\mathrm{O}$ tutor informou que o animal havia cruzado há aproximadamente um mês. Ao exame físico, o animal encontrava-se apático, taquicárdico e com abdômen distendido. Foi coletado sangue e realizada avaliação ultrassonográfica que revelou presença de um feto no corno direito, cujo diâmetro biparietal indicou idade aproximada de $47 \pm 3$ dias. No corno esquerdo foi observada presença de conteúdo hipoecogênico, levantando suspeita de reabsorção fetal ou piometra. O exame bioquímico indicou aumento de fosfatase alcalina $(281.9 \mathrm{U} / \mathrm{l})$ e ureia $(52,05 \mathrm{mg} / \mathrm{dl})$, alterações comumente encontradas em piometra. Um segundo exame ultrassonográfico, realizado cinco dias depois, indicou aumento do diâmetro do corno esquerdo e de seu conteúdo. Também foi realizado raio $\mathrm{X}$, onde foi confirmada a presença de apenas um feto e aumento do volume uterino. Após oito dias, o animal foi reavaliado, encontrando-se taquicárdico, taquipneico, com ligeira hipotermia, mamas ingurgitadas com presença de secreção láctea e muco vaginal. $O$ ultrassom indicou organogênese completa do feto. Diante da maturidade fetal e necessidade de ovariosalpingohisterectomia devido à presença de piometra no corno esquerdo, foi realizada cesariana radical neste mesmo dia, com nascimento de um neonato saudável. Para descartar a suspeita do conteúdo do corno esquerdo ser proveniente de reabsorção fetal, ele foi aberto, lavado e minuciosamente inspecionado em busca de zona de aderência, que não foi encontrada. Casos como esse podem ocorrer devido à presença prévia de infecção no trato genital, que no momento da cópula é carreada até o útero; presença de infecção uterina que começou seu desenvolvimento devido ao aumento de progesterona levando à imunosupressão local; e formação inadequada do tampão mucoso, viabilizando ascensão de patógenos. Em sua rotina, o obstetra constantemente é desafiado quanto ao limiar entre optar pela saúde da mãe ou manter a gestação. Esse caso sugere que um acompanhamento cauteloso possibilita tanto a sobrevivência materna quanto a fetal.

Palavras-chave: Piometra. Cadela. Viabilidade fetal. Gestação. 


\section{OTOHEMATOMA EM CAPRINOS}

Otohematoma in goats

LIMA, R. P.; BRAZ, K. M. G.; CARLI, F. F.; LUCAS, F. A.

Resumo: O Otohematoma $(\mathrm{OH})$ é um acúmulo de sangue dentro da cartilagem auricular ocasionado por traumas, de diversas etiologias. Em cães e gatos, $\mathrm{OH}$ são causados por otite externa, devido ao prurido apresentado e $o$ ato de coçar a orelha, sendo mais comum em animais de orelhas pendentes em relação a animais de orelhas eretas. Já em equídeos e ovinos as causas mais comuns são os traumas causados por movimentação e fricção excessiva da cabeça, em decorrência a ectoparasitas e infestação por moscas. $\mathrm{O} \mathrm{OH}$ apresenta-se como tumefações flutuantes, tensas e por vezes dolorosas, que variam em tamanho e posição. Embora os otohematomas possam ser encontrados nas duas faces da orelha, geralmente ocorrem apenas na superfície côncava. Um caprino, macho, boer, com um ano de idade, foi atendido no Hospital Veterinário Luiz Quintiliano de Oliveira, da Faculdade de Medicina Veterinária da Universidade Estadual Paulista (Unesp Araçatuba) apresentando paralisia de membros pélvicos e ataxia de membros torácicos. Ao raio $\mathrm{X}$ foi diagnosticada uma fratura de vértebra lombar L3. Durante a inspeção do animal, a orelha direita apresentava-se com aumento de temperatura local e aumento de volume na porção côncava do pavilhão auricular. Foi realizada uma punção aspirativa e determinada a presença de secreção serosanguinolenta. Foi realizada uma incisão para drenagem de todo o conteúdo com posterior sutura simples interrompida com nylon $0,35 \mathrm{~mm}$ nas duas bordas das extremidades, deixando um local central para limpeza e drenagem da secreção. A limpeza diária foi realizada com água oxigenada, iodo povidona tópico e enfaixado com atadura e esparadrapo. Após cinco dias, observando-se recidiva da coleção serosanguilolenta, foi realizado nova drenagem do $\mathrm{OH}$ com incisão em formato de "S" na superfície côncava do pavilhão auricular. Após drenagem de todo o conteúdo, foram efetuadas suturas padrão Donnatti, abrangendo pele e cartilagem adjacente. $\mathrm{O}$ pós-operatório consistiu em terapia anti-inflamatória com flunixin meglumine $1,1 \mathrm{mg} / \mathrm{kg} / \mathrm{IM} / \mathrm{SID}$, durante três dias. $\mathrm{O}$ animal veio a óbito em quatro dias por outras complicações e durante esse período não houve recidiva do $\mathrm{OH}$. Concluiu-se que o $\mathrm{OH}$ foi causado por traumas repetitivos no pavilhão auricular, devido à impossibilidade de locomoção causada pela fratura de vértebra lombar. Não foram encontrados outros relatos sobre $\mathrm{OH}$ na espécie caprina, tema muito frequente em cães, gatos, ovinos e equídeos. A técnica cirúrgica em "S" foi eficaz, pois sustou o acúmulo de sangue.

Palavras-chave: Caprino. Orelha. Otite. Otohematoma.

44. LEVANTAMENTO DE ZOONOSES ATENDIDAS NA CLÍNICA MÉdICA DE GRANDES ANIMAIS DA FMV-UNESP, DE 1994 A 2017. . ARAÇATUBA/SP, BRASIL

Survey of zoonoses attended at the Medical Clinic of Large Animals of FMV-Unesp between 1994 and 2017, Araçatuba, São Paulo state, Brazil

BARBOSA, S. O.; ROSADO, R. S.; DONADON, A. E. S.; LIMA, R. P.; FARIA, A. P. P. A.; SCANTAMBURLO, D. D.; BORGES, A. S.; CADIOLI, F. A.; FEITOSA, F. L. F.; MENDES, L. C. N.

Resumo: As zoonoses, doenças ou infecções naturalmente transmitidas entre os animais vertebrados e os seres humanos, podem ter diferentes agentes etiológicos, incluindo bactérias, vírus, fungos e protozoários. Atualmente, estima-se que há mais de 200 doenças classificadas como zoonoses e, apesar da aplicação de medidas de controle e prevenção, os países em desenvolvimento ainda possuem alta incidência de tais doenças, o que indica deficiências na vigilância epidemiológica e controle. Dentre as dificuldades observadas, deve ser destacado o diagnóstico rápido e preciso, a determinação das vias de eliminação e transmissão, bem como o registro e notificação de casos positivos, que são considerados os principais pontos falhos. Ainda há muitos entraves com relação à identificação das infecções que podem ser confundidas com outras doenças, assim como o registro e subnotificação de casos positivos. Apesar de existir uma predileção absoluta, algumas zoonoses apresentam-se como doenças de caráter ocupacional. Entre os profissionais mais susceptíveis a esses riscos, são elencados os médicos-veterinários, os tratadores de animais, os funcionários de abatedouros e os proprietários ou tutores, que constantemente são expostos ao contato direto ou indireto com animais e/ou suas secreções. Diversos trabalhos têm demonstrado que o nível de conhecimento da população em geral sobre zoonoses é ainda insuficiente, principalmente no que se refere às medidas básicas de prevenção, como higiene pessoal e ambiental. O risco de transmissão de agentes infecciosos, além de importante para a saúde ocupacional individual, tem grande relevância para a saúde pública. Este trabalho foi um estudo retrospectivo delineado, por quantificar e identificar as principais zoonoses atendidas pela 
Clínica Médica de Grandes Animais (CMGA) no Hospital Veterinário Luiz Quintiliano de Oliveira, da Faculdade de Medicina Veterinária da Universidade Estadual Paulista (Unesp Araçatuba), no período compreendido entre os anos de 1994 a 2017. Com base nos livros de registros da casuística do hospital foram, no referido período, 4817 casos atendidos na CMGA, dos quais $96(1,99 \%)$ eram zoonoses. Dentre essas, foram diagnosticadas as seguintes doenças: dermatofitose $(37,5 \%)$, ectima $(21,88 \%)$, dermatofilose $(18,75 \%)$, leptospirose $(12,5 \%)$, raiva $(5,21 \%)$, actinobacilose $(3,12 \%)$ e criptosporidiose (1,04\%). A educação em saúde é um processo ativo e contínuo, que se faz necessário para promover mudanças no conhecimento, atitudes e comportamento das pessoas frente aos problemas sanitários, visando melhorar as condições diretas e indiretas da saúde das pessoas. Portanto, os médicos-veterinários, por serem a classe profissional com maior esclarecimento sobre a temática, devem sempre estar em contato com proprietários, tratadores e demais envolvidos nas atividades agropecuárias, para instruí-los na prevenção de zoonoses tanto no rebanho quanto nos humanos, a fim de reduzir gradativamente a ocorrência dessas doenças e seus impactos socioeconômicos.

Palavras-chave: Zoonoses. Grandes Animais. Saúde pública. Prevenção.

\section{CERATOESCLEROPLASTIA COM MEMBRANA DE PBAT/TPS E MEMBRANA AMNIÓTICA FELINA NO TRATAMENTO DE MELANOCITOMA LÍMBICO EM UM CÃO: RELATO DE CASO}

Keratoescleroplasty with PAT/TPS and feline aminiotic membrane in the treatment of limbal melanocytoma in a dog: case report

PEDROZA, T. M.; BENGUELLA, H.; TRUJILLO, D. Y.; ALCANTRA, B. M.; LUCAS, A. A.; ANDRADE, A. L.

Resumo: Este trabalho relata um caso de melanocitona límbico canino tratado por meio de ceratectomia lamelar e conjuntivo esclerectomia total, utilizando-se a membrana de Poli-butileno adipato-co-tereftalato (PBAT) e Amido Termoplástico (TPS)/(PBAT/TPS), como alternativa terapêutica na reparação cirúrgica cosmética em associação ao emprego da membrana amniótica felina. Uma cadela, poodle, cinco anos, foi atendida no hospital veterinário da Faculdade de Medicina Veterinária da Universidade Estadual Paulista (FMV-Unesp Araçatuba), apresentando crescimento de uma neoformação envolvendo córnea, limbo e conjuntiva do canto temporal superior do olho direito, com aproximadamente $1,0 \mathrm{~cm}$, de coloração amarronzada e evolução de um ano. A análise de amostras citológicas revelou, presuntivamente, tratar-se de melanocitona. O animal apresentava bom estado de saúde, atestado por exames. Preconizou-se realizar ceratectomia lamelar e conjuntivo esclerectomia penetrante com margem de $0,2 \mathrm{~mm}$. Ato contínuo, foi realizada a betaterapia com Estrônico-9o (Sr-90), aplicada diretamente sobre o leito operado, totalizando $1.970 \mathrm{cGy}$. Para reparar os defeitos teciduais gerados, principalmente àquele referente à esclerectomia penetrante, foi utilizada a membrana de PBAT/TPS (60:40) recortada no formato do defeito tecidual criado. A membrana foi suturada em pontos simples isolados, empregando-se mononáilon 8-o. Finalmente, foi utilizada a membrana amniótica felina preservada em glicerina sobre a membrana de PBAT/ TPS e córnea desnuda, aplicada sob sutura em padrão contínuo. Por medidas pós-operatórias, foram utilizados colírios antibióticos, anti-inflamatório não esteroidal e imunomodulador. O exame anatomopatológico revelou a presença de proliferação de cachos de melanócitos poligonais com pigmento de melanina dentro do seu citoplasma, moderada displasia se distendendo até a conjuntiva bulbar, com margens livres. A membrana foi removida aos 30 dias pós-operatório, conjuntamente com a sutura. As neoplasias melanocíticas constituem 2,6\% de todas as neoplasias caninas, sendo $81 \%$ delas de caráter maligno. Os raios UVA e UVB podem estar envolvidos na mutação dos melanóticos, mas quase sempre induzem a ocorrência de melanoma, cuja ressecção cirúrgica radical e radioterapia estão indicadas. Nenhuma característica clínica distingue as proliferações melanocíticas benignas das malignas, sendo necessário o emprego de outros recursos diagnósticos para diferenciá-las. Neste caso cumpre ser destacada a boa evolução pós-operatória obtida com o emprego da membrana sintética, que permitiu a contenção imediata do tecido uveal após a esclerectomia, devido à sua resistência, impedindo que sua protrusão persististe. Também é provável que a betaterapia tenha influenciado positivamente impedindo a recorrência do tumor, apesar do seu caráter benigno. Concluiu-se que a membrana de PBAT/TPS pode ser uma alternativa viável em procedimentos desta natureza, com a vantagem de impedir a protrusão do tecido uveal, inerentes aos casos de afinamentos esclerais e/ou excisão escleral pós-cirúrgicos.

Palavras-chave: Cão. Melanocitoma. Neoplasia ocular. PBAT/TPS. Membrana amniótica. 